\title{
La noción de cargo público en algunas fuentes jurídicas romano-bizantinas ${ }^{1}$
}

\author{
FRANCISCO J. ANDRÉS-SANTOS ${ }^{2}$
}

\section{RESUMEN}

Este artículo analiza los medios para expresar la noción de cargo público en algunas fuentes jurídicas bizantinas de finales del siglo IX e inicios del siglo X. El resultado a que se llega es que puede observarse un uso del término ó $\varphi \varphi$ íкı como un mero calco lingüístico del término técnico latino officium, pero que, a medida que la lengua de las fuentes jurídicas bizantinas se fue "exhelenizando", el término fue desapareciendo, para ser sustituido por expresiones más propias de la lengua griega tradicional.

Palabras clave: Derecho administrativo, Derecho romano, Historia del derecho, Magistrado, Servicio público.

1 El presente trabajo se realiza en el marco del proyecto de investigación FFI2015-65118C2-1-P, financiado por el Ministerio de Economía y Competitividad de España y el Fondo Social Europeo.

2 Doctor en Derecho, licenciado en Filosofía y Letras, y catedrático de Derecho Romano de la Universidad de Valladolid, Valladolid, España. Correo-e: fjandres@der.uva.es Fecha de recepción: 25 de julio de 2016. Fecha de modificación: 19 de agosto de 2016. Fecha de aceptación: 2 de septiembre de 2016. Para citar el artículo: Andrés-Santos, F. J. "La noción de cargo público en algunas fuentes jurídicas romano-bizantinas", Revista digital de Derecho Administrativo, n. ${ }^{\circ} 16$, segundo semestre, Universidad Externado de Colombia, 2016, pp. 223-262. DOI: http://dx.doi.org/10.18601/21452946.n16.11. 


\title{
The Expression of Public Office in some Roman-Byzantine Legal Sources
}

\author{
ABSTRACT
}

This paper analyzes the methods for understanding the notion of public service in some Byzantine legal sources between the end of the 9th and the beginning of the $10^{\text {th }}$ centuries. From this, it can be ascertained that the use of the word $o \varphi \varphi$ íı $v_{\nu}$ corresponds to a mechanic translation of the legal technical term officium in Latin (transliteration), but as the Byzantine legal sources became progressively "exhellenized" the term started to disappear and be replaced by more traditional Greek words.

Keywords: Administrative Law, Roman Law, History of Law, Magistrate, Public Service.

\section{INTRODUCCIÓN: LA RECUPERACIÓN DEL DERECHO JUSTINIANEO EN BIZANCIO Y EL "RENACIMIENTO MACEDONIO". ÁMBITO DE LA INVESTIGACIÓN PROPUESTA}

La recuperación del derecho justinianeo en Bizancio $^{3}$ durante los siglos centrales de la Edad Media a través de lo que se ha denominado "renacimiento jurídico macedonio" constituye, según algunos prominentes historiadores del derecho ${ }^{4}$, un auténtico fenómeno de "recepción jurídica" parangonable, en gran media, con el proceso de recepción por antonomasia que se dio en Bolonia y otras universidades italianas desde finales del siglo XI. Esta "recepción" bizantina presentó, no obstante, características peculiares que la hacen bien distinta de la recepción occidental, y de cualesquiera otros fenómenos de recepción jurídica a lo largo de la historia. En efecto, como es sabido, en la historiografía jurídica bizantinista se suele hablar tradicionalmente de "renacimiento jurídico macedonio" para hacer referencia a un movimiento de renovación del ordena-

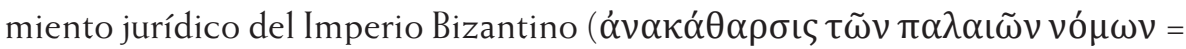
repurgatio veterum legum o "purificación de las antiguas leyes") llevado a cabo por

3 Sobre la continuidad del derecho romano en el Imperio Bizantino vid., por todos, ANTONIO FERNÁNDEZ De BuJÁN, Derecho público romano. Recepción, jurisdicción y arbitraje, 13. ${ }^{a}$ ed. Cizur Menor (Navarra): Civitas-Thomson Reuters, 2010, 213 ss

4 P. ej., MARIE-THERESE, FÖGEN, "Reanimation of Roman Law in the ninth century: remarks on reasons and results", Byzantium in the Ninth Century. Dead or Alive? Papers from the Thirteenth Spring Symposium of Byzantine Studies, Birmingham: Routledge, Leslie Brubaker (ed.), 1996, 11 ss. 
diversos emperadores de la dinastía "macedonia" entre Basilio I y Constantino IX Monómaco, es decir, entre la segunda mitad del siglo IX y mediados del siglo XI. Ya por su denominación resulta evidente que dicho movimiento jurídico se encontraría conectado con lo que en la historia general de Bizancio se ha llamado el "renacimiento macedonio", que afectaría igualmente a otras áreas de la cultura, como la literatura o las artes plásticas, así como a la vida social y política en general. Sin embargo, dicha etiqueta es en realidad errónea, y ello por dos motivos: primero, porque el emperador que inauguró la dinastía, Basilio I, no era verdaderamente macedonio de origen, sino armenio o tracio ${ }^{5}$; $y$, en segundo lugar, porque los inicios de este movimiento de renovación cultural se remontan más atrás en el tiempo, concretamente a los reinados de los emperadores Teófilo (829-842) y Miguel III (842-867), por el impulso de destacadas figuras políticas y culturales del siglo IX, como fueron el ministro Bardas y el patriarca de Constantinopla Focio ${ }^{6}$.

Sea como fuere, lo cierto es que la denominación ha tenido éxito en la historiografía, en la medida en que los primeros testimonios escritos al respecto -sobre todo en el ámbito jurídico- se remontan a la época del emperador Basilio I (867-886) ${ }^{7}$. Como es sabido, este emperador impulsó una ambiciosa tarea de reorganización del Imperio y, en concreto, del material jurídico existente en Bizancio en ese momento, bajo el signo de la restauración del esplendor del antiguo derecho contenido en el Corpus iuris justinianeo, que había sido fuertemente modificado $-\mathrm{y}$, en gran parte, olvidado- por sus antecesores, principalmente los emperadores de la dinastía iconoclasta de los Isaurios (717-802). En efecto, bajo el gobierno del emperador León III el Isaurio (717-741) y de su sucesor Constantino V Coprónimo (741-775) se adoptó una política de helenización del derecho bizantino y adaptación a las costumbres orientales, que dio como mayor resultado la promulgación, seguramente en el año 741, de una compilación en lengua griega para uso judicial sintetizadora del Corpus iuris, pero con grandes innovaciones tomadas de la práctica jurídica de la época, conocida con el nombre de Ekloge tou nómon (Ecloga, es decir, "selección" o "antología", scil. del Corpus iuris civilis). Basilio I se planteó sustituir esta compilación por una propia, pero mucho más ambiciosa,

5 Vid. al respecto, ANDREAS SCHMINCK, "The beginnings of the 'macedonian' dynasty", Byzantine Macedonia. Identity, Image and History (Papers of the Melbourne Conference, July 1995), Melbourne: Australian Association of Byzantine Studies/Australian Catholic University, John Burke \& Roger Scott (eds.), 2000, 61 ss.

6 Vid. ANDREAS SCHMinCK, "Leges ou nomoi? Le choix des princes slaves à l'époque de Photius

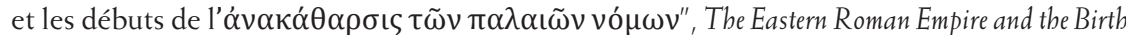
of the Idea of State in Europe/L'Empire romain d'Orient et la genèse de l'idée d'État en Europe, London: Esperia, Spyridion Flogaitis \& Antoine Pantélis (eds.), 2005, 309-316.

7 Sobre la figura de este importante emperador en la historia bizantina, vid. la clásica biografía de AlBeRT VOGT, Basil Ier, empereur de Byzance (867-886) et la civilisation byzantine à la fin du IXe siècle, Paris: Picard, 1908. 
llevado tanto de un desprecio por la actuación de los iconoclastas (cuya obra jurídica consideraba "vaniloquios" y un "atropello de las buenas leyes") como por razones prácticas, y también, por qué no, por un afán de emular la gloria de Justiniano. Esta reforma tendría por objeto reorganizar el material justinianeo, "purificado" de sus normas superfluas y contradictorias y, especialmente, limpio de latinismos en la terminología jurídica, que las traducciones griegas existentes hasta ese momento aún exhibían abundantemente (exbellenismoi). Es presumible que Basilio no llegara a ver nunca en vida la realización de ese proyecto, que sólo pudo culminar su hijo y sucesor León VI (886-912) a través de los Basílicos (tà Basiliká), pero sí es muy probable que durante su reinado, aparte de leyes y otras disposiciones en ese sentido, aparecieran ya algunos trabajos preparatorios de tal compilación, los compendios titulados Eisagoge tou nómon (antes conocida erróneamente como Epanagoge) y Procheiros Nomos (o, simplemente, Prochiron, "manual") -que algunos autores datan a inicios del siglo $\mathrm{X}^{8}{ }^{8}$. En cualquier caso, como resultado de este esfuerzo de restauración del derecho por parte de estos dos emperadores, en menos de cincuenta años aparecieron al menos dos compendios-síntesis (la Eisagoge y el Prochiron), una extensa compilación en sesenta libros (los Basílicos), más de cien "nuevas leyes" o Novelas de León VI y una colección de reglas referidas a los diversos gremios de Constantinopla (el Libro del Eparco), además de otras obras de datación y carácter discutidos. Aparte de esto, en los decenios siguientes se produjo un impresionante florecimiento de la literatura jurídica dedicada a la exégesis, comentario y aplicación práctica de estas compilaciones normativas, que se anticiparía en más de un siglo a la obra de recuperación del derecho justinianeo en Occidente9.

8 Hay una fuerte polémica doctrinal en torno a su verdadera fecha de aparición, a su auténtico carácter normativo y a la relación existente entre ellas: vid. una panorámica general al respecto en THOMAS E. VAN BOCHOVE, "Some Byzantine Law Books. Introducing the Continuous Debate Concerning Their Status and Their Date", Introduzione al diritto bizantino. Da Giustiniano ai Basilici, Pavia: IUSS Press, Jan H. A. Lokin \& Bernhard H. Stolte (eds.), 2011, 239-266, e infra en el texto.

9 Vid. una panorámica general sobre esta época de la historia jurídica bizantina (también conocida como la "época clásica de la literatura jurídica bizantina") en JEAN ANSELME Bernard Mortreuil, Histoire du droit byzantin ou du droit romain dans l'empire d'Orient depuis la mort de Justinien jusqu'à la prise de Constantinople en 1453, vol. II, Paris, 1843-1846 (reimpr. Osnabrück: Otto Zeller, 1966), 1 ss.; LEOPOLD WENGER, Die Quellen des römischen Rechts, Wien: Adolf Holzhausens NFG, 1953, 669 ss.; PETER PIELER, "Byzantinische Rechtsliteratur", en H. HunGER, Die hochspracbliche profane Literatur der Byzantiner, München, 1978, vol. 2, 445 ss.; ID., "Av $\alpha \kappa \alpha \dot{\theta} \theta \alpha \rho \sigma \iota \varsigma \tau \tilde{\omega} v \pi \alpha \lambda \alpha \iota \tilde{\omega} v$ vó $\mu \omega \nu$ und makedonische Renaissance", Subseciva Groningana 3, 1989, 61 ss.; NICOLAAS VAN DER WAL, y LOKIN, Historiae iuris Graeco-Romani delineatio. Les sources du droit byzantine de 300 à 1453, Groningen: E. Forsten, 1985, 78 ss.; FÖGEN, "Reanimation of Roman Law...", cit., 11 ss.; ENRIQUE GÓMEZ ROYO, "Introducción al derecho bizantino", Seminarios Complutenses de Derecho Romano 8, 1996, 182 ss.; JAN H. A. Lokin y Thomas ERnSt Van Bochove, (2011), "Compilazione - educazione purificazione. Dalla legislazione di Giustiniano ai Basilica cum scholiis", Introduzione al diritto 
De entre las muchas obras jurídicas producidas durante este período, en este artículo vamos a fijarnos únicamente en el Prochiron, la Eisagoge y las Novelas de León VI.

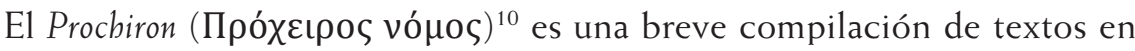
40 títulos que, según su intitulatio, fue publicada y promulgada como texto legal por Basilio I en torno al año $879^{[11]}$, aunque tal vez fuera objeto de una revisión y nueva publicación poco después de la muerte de León VI (912) ${ }^{12}$. Las normas recogidas están tomadas casi en su totalidad del Corpus iuris justinianeo (excepto el título 39, sobre el derecho penal, que se acerca al derecho de la Ecloga isaúrica), a través de la literatura de comentarios de los antecessores y $\sigma \chi 0 \lambda \alpha \sigma \tau$ เкoí de los siglos VI y VII, pero ampliamente helenizadas y enriquecidas con diversas normas tomadas de novelas de Basilio I, por lo que su contenido en ocasiones se desvía del derecho justinianeo ${ }^{13}$.

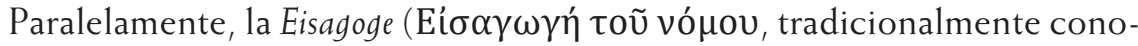
cida como Epanagoge $)^{14}$ es otro compendio de las mismas características que

bizantino. Da Giustiniano ai Basilici, Pavia: IUSS Press, Jan H. A. LOKIn y Bernhard H.

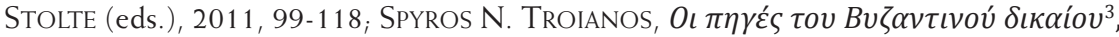

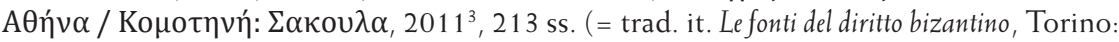
Giappichelli, Pierangelo Buongiorno [ed.], 2015, 137 ss.); GiusePPinA MATTINO, Lex et scientia iuris. Aspetti della letteratura giuridica in lingua greca, Napoli: M. D'Auria Editore, 2012, 92 ss.

10 Ed. en Jus Graecoromanum, vol. II, Athenae: Georgii Fexis \& filii, IOANNES D. ZePOS y PANAGIOTES I. ZEPOS (eds.), 1931, 107-228; nueva ed. del proemio en ANDREAS SCHMINCK, Studien zu mittelbyzantinischen Rechtsbïchern, Frankfurt am Main: Löwenklau Gesellschaft e.

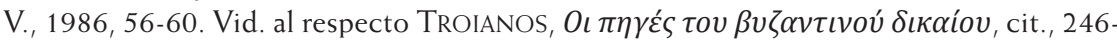
252.

11 En contra, SCHMINCK, Studien..., cit., 98-107, que sitúa su verdadera publicación en el año 907; vid. al respecto, VAN BOCHOVE, "Some Byzantine Law Books...", cit., 248-254 (que

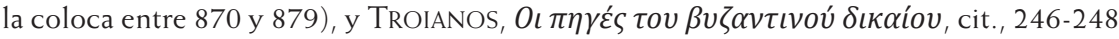
(entre 872 y 879 ).

12 JuAn Signes Codoñer y Francisco J., ANDRÉS SANTOS, La Introducción al Derecho (Eisagoge) del patriarca Focio, Madrid: CSIC, Nueva Roma (Biblioteca Graeca et Latina Aevi posteriores, 28), 2007, 240-246.

13 Vid. Proch. 4.22-27; 11.4; 14.11; 16.14; 21.16; 33.4, 30-32; 34.17; 38.62-64 (vid. KARL

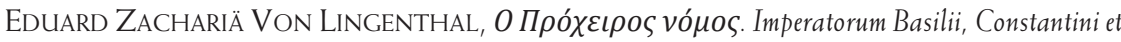
Leonis Prochiron, Heidelberg: J. B. Mohr, 1837, 352); también en los escolios de la Eisagoge (vid. infra inmediatamente en el texto) se hace referencia a disposiciones "de nuestro

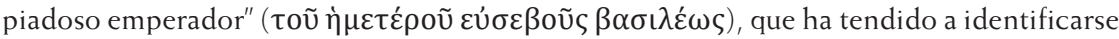
con Basilio I (vid. Signes CODOÑER y ANDRÉS SANTOS, La Introducción al Derecho (Eisagoge)..., cit., 179-181), en contra de esta tesis, SCHMINCK, Studien..., cit., 86-89, que considera que estas desviaciones del derecho justinianeo se deben a intervenciones legislativas de León VI.

14 Ed. en Jus Graecoromanum, vol. II, cit., 229-338; nueva ed. del proemio en SCHMINCK, Studien..., cit., 4-11 (con trad. alemana), reproducido en BERnARD H. STOLTE y MEIJERING (eds.), "The Prooimion of the Eisagoge: Translation and Commentary", Subseciva Groningana

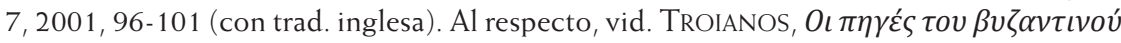


el Procbiron, también en 40 títulos, que según su intitulatio fue elaborada en tiempo del emperador Basilio I en corregencia con sus hijos León y Alejandro (por tanto, entre 880 y 886); sin embargo, una serie de elementos internos y externos del texto ha hecho pensar a muchos estudiosos que la obra nunca llegó a recibir sanción imperial y, por tanto, jamás adquirió valor de ley y se quedó en un mero proyecto privado ${ }^{15}$; no obstante, dado que su redacción probablemente fue inspirada (y quizá en algunos capítulos directamente realizada) por el patriarca Focio ${ }^{16}$, la obra gozó de gran prestigio en los círculos intelectuales y alcanzó cierta fortuna a lo largo de la historia del Imperio en diversos ámbitos ${ }^{17}$. $\mathrm{Al}$ igual que el Procbiron, está compuesto sobre todo de textos procedentes del Corpus iuris civilis, en versión griega tomada de la literatura jurídica de los siglos VI y VII, con algunas variaciones procedentes de la legislación de Basilio $\mathrm{I}_{i}$ pero, a diferencia de aquel, contiene una serie de títulos (1-11) referidos a materias de derecho público y religioso, donde se trata de las relaciones entre el poder político y eclesiástico y se regulan algunas figuras importantes de la jerarquía judicial civil y canónica, en estos títulos, y en algunos capítulos concretos, se hallan textos originales de gran interés, pero totalmente ajenos a la tradición justinianea ${ }_{i}$ asimismo, en materia de derecho privado se observa una mayor influencia que en el Prochiron del derecho de la Ecloga, sobre todo en los campos de las relaciones patrimoniales entre cónyuges y del derecho hereditario, así como en el ámbito del derecho penal. De ahí que su texto resulte, en general, menos utilizable que el del Prochiron con vistas a la crítica del Corpus iuris justinianeo. La obra viene normalmente acompañada en su tradición manuscrita por un aparato de escolios, de autoría y datación desconocidas, que muestran un buen conocimiento del derecho justinianeo y son asimismo utilizables para la crítica textual de este ${ }^{18}$.

Las Novelas ${ }^{19}$ atribuidas al emperador León VI (al que también se adjudican otras obras de carácter jurídico, como el Libro del Eparco, sobre la regulación

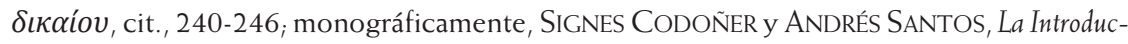
ción al Derecho (Eisagoge)..., cit. (con trad. española); vid. una síntesis en ANDRÉS SANTOS, FRANCISCO J., "La Eisagoge de Focio: un compendio jurídico del siglo IX", Revista General de Derecho Romano, 9, 2007 [online: http:/www.iustel.com].

15 Signes Codoñer y Andrés SANTOS, La Introducción al Derecho (Eisagoge)..., cit., 165-180, en contra, SCHMINCK, Studien..., 72-75, y ThOmas E. VAN BOCHOVE, To Date and Not to Date. On the Date and Status of Byzantine Law Books, Groningen: Egbert Forsten, 1996, 27, que sostienen su carácter oficial.

16 Signes CodoñER y ANDRÉS SANTOS, La Introducción al Derecho (Eisagoge)..., cit., 147-160

17 Jehan DE Malafosse, s. v. 'Épanagogè', en Dictionnaire de Droit Canonique, vol. v, Paris: Libraire Letouzey et Ané, Raoul Naz (dir.), 1953, 354-362.

18 Vid. al respecto Signes CODOÑER y ANDRÉS SANTOS, La Introducción al Derecho (Eisagoge)... cit., 169-182.

19 Sobre esta obra, vid. ahora Signes CodoñER, JuAn, "The Corpus of Leo's Novels: Some Suggestions Concerning Their Date and Promulgation", Subseciva Groningana 8, 2009, 1-33; 
de los gremios de Constantinopla, un Taktikon, y algunas otras más, además de la publicación definitiva de los Basílicos iniciados en el reinado de su padre $)^{20}$ constituyen una amplia batería de normas legislativas (en total, 113 novelas recogidas oficialmente en una colección [Sylloge CXIII Novellarum], más algunas otras que quedaron fuera de ella [Novellae extravagantes] ${ }^{21}$ ) dictadas con un decidido ánimo reformista del derecho vigente, además en aspectos centrales de la vida social, como el derecho de familia y el derecho de sucesiones, que inciden directamente en capítulos básicos de la compilación justinianea. Es justo por ese afán abiertamente reformista y emulador de Justiniano ${ }^{22}$ por lo que en las Novelas de León aparecen abundantes referencias de contenido a las leyes de Justiniano que León pretende derogar o, al menos, modificar. De ahí que estas piezas legislativas puedan prestarse más que otras a una comparación con los pasajes del Corpus iuris civilis. Ahora bien, al mismo tiempo, dada la decidida vocación de estilo personal que presenta la escritura de León ${ }^{23}$, esas mismas referencias a la legislación justinianea aparecen expresadas de un modo particular que hace difícil proceder a una verdadera confrontación textual con el discurso de las leyes compilatorias.

No son estas, en realidad, las obras más significativas desde el punto de vista del derecho administrativo de la época, de hecho, del periodo macedonio han llegado hasta nosotros un buen número de testimonios que reflejan ampliamente las importantes transformaciones que en la organización de la administración bizantina se produjeron en ese periodo ${ }^{24}$. Además, naturalmen-

ID., "Las Novelas de León VI el Sabio", Introduzione al diritto bizantino..., cit., 267-321 (con

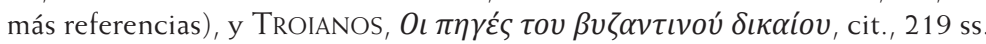

20 Sobre el reinado de León VI, y también sobre su personalidad y su obra, vid. TouGHER, Shaun, The Reign of Leo VI (886-912). Politics \& People, Leiden, New York, Köln: Brill, 1997.

21 Ed. estándar de Pierre Noailles y Alphonse Dain (Les Novelles de Léon VI le Sage, Paris: Les Belles Lettres, 1944), reproducida (con trad. griega moderna) en TROIANOS, SPYROS N.,

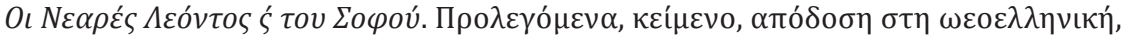

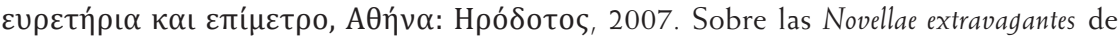
León, vid. SCHMINCK, ANDREAS, "Novellae extravagantes Leons VI", Subseciva Groningana, 4, 1990, 195-209.

22 Vid. Francisco BarTOL, "Leo VI Philosophus adversus lustinianum?", SDHI, 73, 2007, 445 450.

23 Vid. VAN Der Wal y LOKIN, Historiae iuris graeco-romani delineatio..., cit., 86.

24 Sobre la administración bizantina en general, y en época de los Macedonios en particular, vid. John B. BuRY, The Imperial Administrative System in the Ninth Century, with a Revised Text of the Kletorologion of Pbiloteos, London, 1911 (reimpr. New York: Burt Franklin, 1958), GEORG KOLIAS, Ämter- und Würdenkauf im früh- und mittelbyzantinischen Reich, Athen: Verlag der Byzantinisch-neugriechischen Jahrbüchern, 1939; LOUIS BREHIER, Las instituciones del Imperio bizantino (trad. esp. J. Almoina), México: Unión Tipográfica Ed. Hispano Americana, 1956, 78-144; HÉLÈNE AHRWEILER, (1960), "Recherches sur l'administration de l'empire byzantin aux IX"-Xe siècles", Bulletin de Correspondence Hellénique 84, 1960, 1-109 (= Études sur les structures administratives et sociales de Byzance, London 1971, VIII); RODOLPHE GUILLAND, Recherches sur les institutions byzantines, vol. I, Berlin/Amsterdam: Akademie Verlag/Hakkert, 
te, de todo el material contenido en el enorme corpus de los Basílicos, de esta época también poseemos (aparte de los documentos de la práctica, como las cartas y diplomas imperiales, crisóbulos, documentos manuscritos de archivos oficiales y monásticos, escritos notariales, etc.) diversas obras normativas y doctrinales con un contenido específicamente administrativo. Así, por ejem-

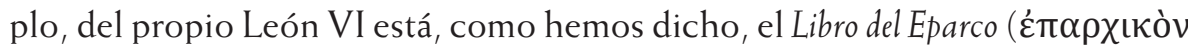
$\beta \iota \beta \lambda$ íov $)^{25}$, una colección de disposiciones regulatorias de la actividad de los gremios de Constantinopla; o también el libro de Taktika Leonis ${ }^{26}$, atribuido al mismo emperador, que contiene normas referidas a la administración militar del Imperio a finales del siglo IX e inicios del siglo X. Otros Taktika, pero cuyo objeto es esta vez la descripción de la jerarquía de los funcionarios imperiales, son el Taktikon de Beneševič (por el nombre de su primer editor) ${ }^{27}$, de los años 943-944, y el Taktikon codicis Scorialensis graeci $R-I I-11^{[28]}$, realizado entre el año 971 y el 975, así como el Kletorologion ${ }^{29}$, de 899, escrito por el protospatario y atriklines de la corte imperial Filoteo, que recoge la posición jerárquica de los funcionarios imperiales y los invitados ajenos a la administración en los banquetes oficiales en la corte, el cual constituye una fuente esencial para el

1967; GÜNTER WeISS, Oströmische Beamte im Spiegel der Schriften des Michael Psellos, München: Univ. Inst. für Byzantinistik und Neugriechische Philologie, 1973; ANDRÉ GuILlOu, La civilisation byzantine, Paris: Arthaud, 1974, 108-195; FriedHELM WINKELMANN, Byzantinische Rang- und Ämterstruktur im 8. und 9. Jabrbundert, Berlin: Akademischer Verlag, 1985; JEANClaude CHEYNet, Le monde byzantin, II. L'empire byzantine (641-1204), Paris: PUF, 2006, 125-150; JOHN HALDON, "Structures and administration", en The Oxford Handbook of Byzantine Studies, Oxford: OuP, Elisabeth Jeffreys, John Haldon \& Robin Cormack (eds.), 2008, 539-553 (con más lit. en pp. 552-553). Sobre la problemática general del derecho administrativo en la Antigüedad romana (incluida la época postclásica hasta Justiniano), vid. ANTONIO FERNÁNDEZ DE BujÁN, "Instituciones, hechos y actividad de orden administrativo en la experiencia jurídica romana", Derecho administrativo bistórico, Santiago de Compostela: Escola Galega de Administración Pública, Antonio Fernández de Buján (dir.), 2005, 119-157; ID., Derecbo público romano..., cit., 237 ss.; ID., "Hacia un tratado de derecho administrativo y fiscal romano", Hacia un Derecho Administrativo y Fiscal Romano, Madrid: CEU/Dykinson, A. Fernández de Buján (dir.), G. Gerez Kraemer \& B. Malavé Osuna (eds.), 2011; ID., "Derecho Administrativo Romano: instituciones, conceptos, principios y dogmas", Revista general de Derecho Romano, 16, 2011 [online: www.iustel.com] (con más lit.).

25 Ed. en JOHANNES KODER, Das Eparchenbuch Leons des Weisen. Enführung, Edition, Übersetzung und Indices, Wien: Verlag der Österreichischen Akademie der Wissenschaften, 1991. Vid.

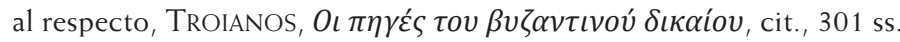

26 Ed. en Patrologia Cursus Completus. Pars Graeca, vol. CVII, Paris: Garnier Fratres, Jacques Paul Migne (ed.), 1857-1866, 672-1120; VÁRI, RESZÖ, Leonis imperatoris Tactica Const. I-XIV § 38, vols. I-II/1, Budapest: Typis Regiae Universitatis Scientiarum Budapestinensis, 1917-1922

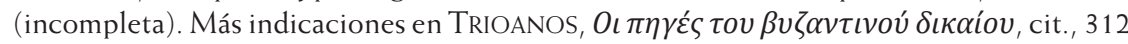
$\mathrm{s}$.

27 Ed. en Nicolas OiKOnOMIDES, Les listes de préséance byzantines des IX et X $X^{e}$ siècles, Paris: CNRS, Paul Lemerle (dir.), 1972, 246-262.

28 Ed. en OiKonOmides, Les listes de préséance..., cit., 263-277.

29 Ed. en OIKONOMIDES, Les listes de préséance..., cit., 81-235. 
conocimiento de la estructura administrativa del Imperio a nivel central en los inicios de la dinastía macedonia. Otra fuente muy interesante sobre la administración periférica durante el Imperio bizantino medio la constituye la obra

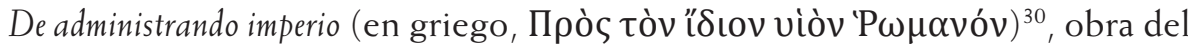
erudito emperador Constantino VII Porfirogénito (913-959), de los años 948 a 952, que constituye sustancialmente un tratado sobre política internacional y relaciones diplomáticas y contiene numerosas informaciones de tipo cultural, etnográfico y organizativo de los diversos pueblos integrados en el Imperio en ese momento. También se atribuye a ese emperador la obra titulada De cerimoniis $^{31}$, que recoge el ceremonial de la corte imperial, pero que también incluye algunos procedimientos inherentes a determinadas instituciones del Imperio, al modo de una especie de tratado "constitucional"32. O, por fin, también de

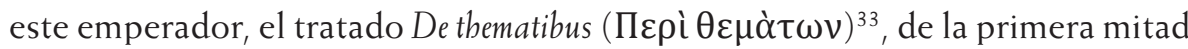
del siglo $X$, en el cual se describen las distintas circunscripciones (themata o "temas") en que se dividía el Imperio a efectos administrativos y defensivos, y la reorganización de las provincias desde un punto de vista histórico; es una obra más histórica y erudita que jurídica, por lo que su utilidad para la reconstrucción de la praxis administrativa de su época es bastante limitada ${ }^{34}$. Sobre la administración fiscal es muy relevante el llamado Tractatus Asbburner (por el nombre de su primer editor) ${ }^{35}$, redactado entre el año 913 y el 1139, en el cual se describen los funcionarios encargados del aparato fiscal y sus competencias, así como los sistemas aplicados para la medición de las tierras a efectos impositivos; no tenía un carácter oficial, sino que era más bien un prontuario práctico destinado a la formación de quien debiera desempeñar la

30 Ed. en Gyula Moravcsik y Romilly J. H. Jenkins, Constantine Porpbyrogenitus: De administrando imperio, vol. I: Greek Text and English Translation, Washington: Dumbarton Oaks

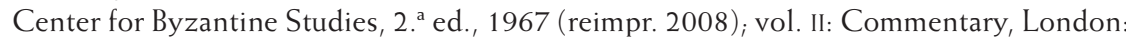
University of London Athlone Press, Romilly J. H. Jenkins et al. (eds.), 1962 (reimpr. Washington: Dumbarton Oaks Center for Byzantine Studies, 2012); vid. al respecto,

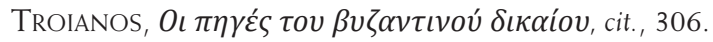

31 Ed. de ReISKE, Johann JAKOB, Constantinus Porphyrogenitus: De cereimoniis aulae byzantinae, vols. I-II, Bonn: E. Weber, 1829-1830; más moderna, pero incompleta, ALBERT VOGT, Constantin VII Porpbyrogénète: Le Livre de cérémonies, vols. I-II, Paris: Les Belles Lettres, 1935-1940 (3. ${ }^{a}$ reimpr. 2006).

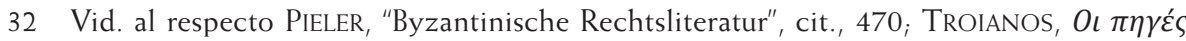

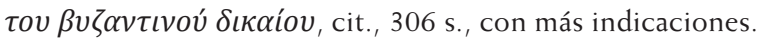

33 Vid. Agostino Pertusi, Constantino Porfirogenito, De thematibus. Introduzione, testo critico, commento Città del Vaticano (Studi e Testi, 160), 1952.

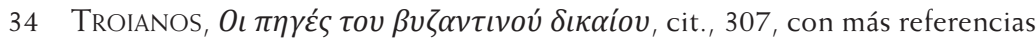

35 La obra se encuentra contenida en el manuscrito Marcianus Graecus 173. Ed. de AsHBURNER, WALTER, "A Byzantine Treatise on Taxation", Journal of Hellenistic Studies 25, 1925 , 76-84; nueva ed. y estudio en DÖLGER, FRANZ JOSEPH, Beiträge zur Geschichte des byzantinischen Finanzverwaltung, besonders des 10. und 11. Jabrbunderts, Leipzig-Berlin: Teubner, 1927 (reimpr. Hildesheim: Olms, 1960), 113-156. 
función de epópte (esto es, funcionario encargado de la tasación de las tierras) y del personal a su servicio en cada uno de los themata ${ }^{36}$.

Las razones para limitar este estudio a las obras citadas son de diversa índole. Por un lado, hay una razón práctica: resulta imposible abordar en un trabajo de estas características la totalidad de las cuestiones referidas al uso de la terminología sobre el cargo público (incluso limitándonos únicamente al uso de un determinado término alusivo al respecto) en todas las fuentes disponibles; es preciso, por tanto, hacer una selección en cualquier caso, y las obras que hemos señalado resultan manejables por su extensión. Pero hay razones también sustanciales. Por un lado, se trata de obras muy tempranas dentro del movimiento del "renacimiento jurídico macedonio": es decir, son obras hasta cierto punto "inaugurales" del movimiento, y dan cuenta, por tanto, de manera muy precisa, de los ideales restauradores que movieron a los primeros emperadores de la dinastía. Conservan, además, por eso mismo, un punto de conexión con el pasado jurídico romano (aun presente en su mentalidad) mucho más intenso que otras obras que vendrían con posterioridad, y particularmente las obras de temática más específicamente administrativa, que están más apegadas a las necesidades prácticas de su época y, por tanto, reflejan con menor intensidad la permanencia y el sentido intemporal que tenían las categorías jurídicas romanas en el seno del Imperio bizantino. Por ello su estudio puede resultar particularmente interesante. Por otra parte, en cualquier caso, para averiguar el significado real de cualquier término técnicojurídico de las compilaciones griegas, resulta imprescindible rastrear toda la historia de los textos en cuestión y contrastar sus resultados con los usos de la literatura jurídica de su época, e incluso de las posteriores ${ }^{37}$. Al observar cualquiera de esos términos aparecidos en las fuentes bizantinas se hace necesario, pues, analizar si responde a una traducción mecánica de un término original latino, o bien se trata de una traducción adaptadora de antiguos conceptos o instituciones romanas a una realidad social y jurídica muy distinta. Y viceversa, en ocasiones, la traducción fiel de las viejas instituciones romanas exige la utilización de términos griegos que, en su significado originario, diferían fuertemente del sentido nuevo que cobraban en el contexto del lenguaje jurídico bizantino, de modo que, por ese medio, en realidad, los juristas y los técnicos procedían también a sutiles transformaciones en la lengua ordinaria y contribuían a la evolución histórica de la misma - un fenómeno que se ha dado en todas las épocas en que ha existido una jurisprudencia de cierto nivel científico, y al que la nuestra en modo alguno supone una excepción. De ahí,

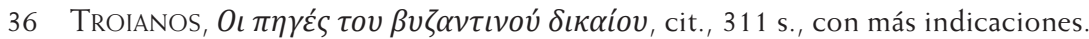

37 Vid. al respecto la contribución de ThOMAS ERNST VAN BOCHOVE, "The Basilica between Quellenforschung and Textual Criticism", Textual Transmission in Byzantium: between Textual Criticism and Quellenforschung, Turnhout: Brepols, Juan Signes Codoñer e Inmaculada Pérez Martín (eds.), 2014, 539 ss. 
por tanto, que un estudio de la evolución de ese léxico jurídico-administrativo exija también un estudio de fuentes como las que aquí nos ocupan, dentro de una economía general de análisis de la evolución histórica de ese léxico en una parte relevante de la cultura europea.

La selección de estas obras, además, no es aleatoria, puesto que, de algún modo, se trata de contrastar la diferencia de lenguajes entre, por un lado, obras formalmente de contenido normativo, como son la Eisagoge y el Prochiron, pero que en realidad son compilaciones de textos llevadas a cabo por juristas particulares -aunque fueran comisionados por el emperador de forma imprecisa-y con un amplio contenido derivado de la tradición jurisprudencial romana o de elaboración doctrinal propia (sobre todo la Eisagoge), y, por otro, una obra de corte legislativo (si bien con unas características muy peculiares), como son las Novelas de León. Hasta cierto punto, la distinción parece reproducir, mutatis mutandis, la vieja dicotomía de la época bajoimperial romana entre leges y iura dentro de las fuentes del derecho. Se trata, por tanto, de verificar hasta qué punto en estas distintas fuentes que proceden de una misma época, incluso puede decirse que del mismo emperador ${ }^{38}$, se utiliza un léxico semejante, o por el contrario diferente, y las razones para ello.

De otra parte, no obstante que ninguna de esas obras pueda considerarse propiamente como una fuente capital en cuestiones de derecho administrativo de la época bizantina media, ello no quiere decir que resulten invalidadas como fuentes útiles para el estudio del léxico jurídico-administrativo del período. Todo lo contrario: justamente el hecho de que no sean obras de carácter primordialmente jurídico-administrativo puede hacerlas aún más interesantes a este respecto desde diversos puntos de vista.

Así, en primer lugar, si bien es cierto que estas fuentes no se centran en las cuestiones de índole administrativa, esto no quiere decir que no las contemplen, sino solo que lo hacen desde una perspectiva más bien marginal: en consecuencia, su regulación de aspectos jurídico-administrativos puede servir de contraste y complemento a lo establecido en otras fuentes sobre cuestiones similares; así, por ejemplo, la Eisagoge da normas sobre ciertas figuras de altos funcionarios de la capital o de provincias, pero desde la perspectiva de su competencia judicial, como órganos de la administración de justicia ${ }_{i}$ esas normas, por lo tanto, pueden servir de instrumento de medición del funcionamiento de esas mismas figuras en otras dimensiones de su actividad pública $\mathrm{y}$, consiguientemente, tienen un valor como materiales para configurar una descripción completa de esas instituciones en el momento histórico que nos

38 En particular las Novelas y el Procbiron, dependiendo, claro está, de la cronología relativa que se adopta en relación con el momento de producción de estas obras: la Eisagoge queda fuera de este cuadro, en todo caso, porque todos los intérpretes coinciden en la idea de que es una obra de la época de Focio; pero no parece ser baladí su influencia en las otras dos obras que nos ocupan. 
ocupa; $y$, viceversa, las normas procedentes de otras fuentes que regulan esas mismas instituciones pueden ser utilizadas como elemento de comparación respecto de la regulación de la Eisagoge y, en consecuencia, servir de vía de interpretación del sentido pragmático de los textos contenidos en esta última. Por tanto, se establece una sugestiva interacción entre unos y otros tipos de fuentes que contribuye a dar una visión más completa de la articulación del Estado bizantino en este período histórico ${ }^{39}$.

En segundo lugar, con independencia de los escasos apartados en los cuales se regulan aspectos propios de la organización administrativa en estas fuentes que nos ocupan, lo cierto es que a lo largo de sus páginas se deslizan, no obstante, con frecuencia numerosos términos que están vinculados a la actividad administrativa. En los capítulos referidos a otras cuestiones, ya sean de derecho privado, derecho penal o derecho eclesiástico, más aún de derecho procesal, aparecen ocasionalmente normas que se acercan más a la regulación administrativa, o bien los términos que se emplean son comunes con la terminología propia de la lengua de la administración pública. El léxico administrativo penetra, pues, de un modo o de otro, en todos los ámbitos de la regulación jurídica, como corresponde a un escenario sociopolítico en el que la presencia del Estado era particularmente intensa. El juego de estas voces en un contexto que no es el propio de la regulación jurídico-administrativa resulta interesante, tanto desde el punto de vista lexicológico como desde el histórico-jurídico, porque permite contrastarlo con el que se encuentra en otras fuentes más especializadas y obtener así tanto una visión más precisa del significado de los termini technici en la lengua jurídica bizantina como una representación más certera del funcionamiento de la administración pública en el Estado bizantino en diversos ámbitos.

Por último, en tercer lugar, el hecho de que la procedencia de la mayor parte de los textos incluidos en la Eisagoge y en el Procbiron sea el Corpus iuris

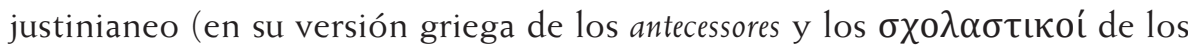
siglos VI y VII), así como que las Novelas de León VI estén escritas sobre todo

39 A pesar de que la primacía de otros tipos de fuentes en la descripción de los elementos institucionales del Estado bizantino, en general, ha hecho suponer que la regulación de estas figuras en la Eisagoge (en menor medida, en las Novelas de León) es absolutamente anticuaria y, por tanto, inútil a los efectos de la representación del cuadro político-institucional real del Estado bizantino en ese período. Sin embargo, es fácil que esta falta de proyección de las normas de la Eisagoge en la concreción normativa de estas figuras en tiempos posteriores se deba más al carácter de mero proyecto normativo no sancionado ni promulgado nunca que esta obra parece presentar (vid. SIGNES CODOÑER y ANDRÉS SANTOS, La Introducción al Derecho (Eisagoge)..., cit., 165-182, con más referencias) que a la presunta falta de realismo de sus disposiciones; debe tenerse en cuenta que, idealmente, el texto estaba redactado para ser publicado como ley por el emperador, de modo que sus disposiciones, especialmente en materia de derecho público, debían sonar verosímiles y factibles a los hipotéticos lectores de la obra que después habían de aceptarla como norma de carácter imperativo. 
con un afán emulador de la obra de Justiniano, hace que el vocabulario que en estas obras aparece relacionado con la organización y la actividad administrativa pertenezca, salvo innovaciones o interpolaciones, a una época distinta a aquella en que, formalmente, estas obras estaban destinadas a aplicarse. Ello resulta también muy sugerente, porque tanto en el análisis del juego de esos términos en la propia economía de las obras en que se incluyen como, sobre todo, en la comparación y contraste con el uso de esos mismos términos en las fuentes propias del período macedonio, o bien en la sustitución en otras fuentes de esos términos por otros para hacer referencia a idénticas o semejantes realidades, podemos observar hasta qué punto el lenguaje jurídico bizantino permaneció estable a lo largo de los siglos, y también en qué medida estas obras que son objeto de nuestra atención resultan ser verdaderas disposiciones con vocación de ser aplicadas en la práctica, o si fueron meros ejercicios académicos de estilo con fines preferentemente propagandísticos.

\section{LA NOCIÓN DE OFFICIUM EN LAS FUENTES JURÍDICAS ROMANAS}

En el antiguo derecho romano, el vocablo fundamental para hacer referencia a lo que en español denominamos hoy cargo público es el término officium. Se trata de un vocablo polisémico, de una notable antigüedad y prestigio en el vocabulario social, político y jurídico romano desde época republicana, con muchos matices y derivaciones ${ }^{40}$. Es un término que, con carácter general, hace referencia a una vaga noción de deber asociado a la fides, por el cual se asume la gestión (opera et ministerium) de intereses ajenos. En su concepto juegan un papel las ideas de solidaridad hacia los conciudadanos y de honestidad absoluta en la realización de tareas por los demás ${ }^{41}$. Es un término que presenta una curiosa evolución semántica, puesto que pasó de tener en sus orígenes unas acepciones de marcado carácter ético-social a adoptar otras de carácter puramente organizativo y administrativo. En el lenguaje jurídico romano se distingue entre officia civilia (referidos a los deberes del ciudadano en sus relaciones con otros

40 Vid. al respecto, con carácter general, CharLes LeCrivain, s. v. 'Officium/Officiales', Dictionnaires des antiquités grecques et romaines d'après les textes et les monuments, Paris: Hachette, Charles Daremberg y Edmond Saglio (dirs.), 1904, 155-156; ARTHUR EDWARD ROMILLY BOAK, s. v. 'Officium', Pauly y Wissowa (eds.), Realenzyclopedie der classischen Altertumswissenschaft, XVII-2, Stuttgart: Alfred Fruckenmüller, 1937, 2045-2056; VitTORIO FrosinI, s. v. 'Officio', Novissimo Digesto Italiano, vol. XI, Torino: Utet, 1965, 773-777; FILIPPO CanCELLI, s. v. "Ufficio (diritto romano)", Enciclopedia del Diritto, vol. XLV, Milano: Giuffrè, 1992, 599-641.

41 Est autem officium quod ita factum est ut eius facti probabilis ratio reddi possit (Cic. fin. 3.58): vid Filippo CANCElli, "Saggio sul concetto di officium in diritto romano", Rivista Italiana per le Scienze Giuridiche 9 (= 92), 1957-1958, 351, 381. 
ciudadanos a nivel privado $)^{42}$ y officia publica. Solo estos últimos nos interesan aquí propiamente, porque solo estos tienen un referente directo en el ámbito administrativo, pero no puede pasarse por alto el hecho de que algunas de las funciones que hoy asociamos a un cargo público venían integradas en el len-

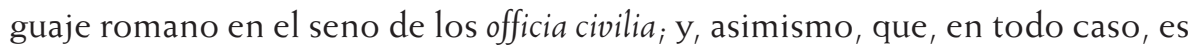
obvio que, aunque fueran de este último tipo, todas las actividades objetivas a las que los romanos asociaban el término "officia" presentaban alguna clase de dimensión o trascendencia pública, ya que implicaban una actuación conforme a reglas morales y a favor de otras personas ${ }^{43}$, por lo que, tanto en su uso técnico como en el atécnico, existe cierta promiscuidad en la utilización de ambos sentidos del término ${ }^{44}$.

El propio sintagma officia publica ofrece una amplia variedad semántica. Bajo este concepto se entendía, en principio, el desempeño de las magistraturas, tanto en época republicana como durante el Principado, a lo que después se fue añadiendo la esfera de competencias del conjunto de sujetos dependientes del príncipe que fueron ocupando los sucesivos departamentos y secretarías (scrinia) introducidos a raíz del incremento de la actividad administrativa del gobierno imperial, y que fueron sustituyendo a los antiguos magistrados. Ello generó el surgimiento de un enorme aparato burocrático fundado en los principios de especialidad y jerarquía que alcanzó su máximo desarrollo en el Bajo Imperio. Por metonimia, el término acabó designando también al conjunto de funcionarios subordinados a un alto cargo de la administración imperial que integraban su departamento. En suma, en la época postclásico-justinianea el término officium (publicum) vino a presentar los siguientes significados ${ }^{45}: 1$ ) deber, en general (sobre todo derivado de los vínculos de parentesco o de amicitia o de moral social), y, en particular, deber de alguien que ostenta un cargo (un magistrado o, en esa época, preferiblemente un funcionario), entendido como la

42 Vid. al respecto CANCELlI, "Saggio sul concetto...", cit., 382-386; Filippo CanCelli, "Nota preliminare sull'officium civile", Studi giuridici in memoria di Filippo Vassalli, vol. I, Milano: Utet, 1960, 229-246; IGNACIO CREMADES, El officium en el derecho privado romano. Notas para su estudio, León: Universidad de León, 1988. Entre las figuras más relevantes de tales officia se encontraban los casos del iudex, el procurator, el tutor, el curator, el defensor y el que ejercía la postulatio y la advocatio procesal por otro (vid. Ulp. D. 50.17.2).

43 CanCelli, "Saggio sul concetto...", cit., pass.

44 Cancelli, "Saggio sul concetto...", cit., 373, 380, CANCELlI, "Nota preliminare...", cit., 236-237; CANCELLI, s. v. 'Ufficio (diritto romano)', cit., 629. De hecho, hay tipos de officia, como p. ej. la función del iudex, o la tutela y la curatela, que en época clásica se consideraban civilia (munera personalia), y, en cambio, en derecho justinianeo son (munera) publica (vid. I. 1.25 pr.).

45 Boak, v. 'Officium', cit.; Hermann Gottlieb Heumann y Emil Seckel, Handlexikon zu den Quellen des römischen Rechts, Graz: Akademischer Druck- und Verlagsanthalt, $10^{\circ}$ ed., 1958 (= Jena: Gustav Fischer, $9^{\circ}$ ed., 1907), 388-389; CANCELl, v. 'Uffizio (diritto romano)', 629-640; CERvEnCA, "Sull'uso del termine 'officium'...", cit. 
esfera de atribuciones que esta persona tiene para desarrollar su función ${ }^{46} ; 2$ ) conjunto de servicios prestados, particularmente de un esclavo o un liberto (ministerium $)^{47} ; 3$ ) en sentido genérico, labor, ocupación, ejercicio de una tarea, aplicación (de una regla $)^{48} ; 4$ ) el conjunto del personal auxiliar o subalterno en un tribunal o, en general, en un órgano administrativo (officiales) ${ }^{49}$. Este último es el significado que irá ganando prevalencia a lo largo del tiempo, hasta acabar convirtiéndose en dominante en el lenguaje de la legislación postclásico-justinianea ${ }^{50}$.

\section{EL SIGNIFICADO DE 'OФФ'IKION EN LAS FUENTES ANALIZADAS}

En el lenguaje jurídico bizantino nos encontramos con cierta frecuencia con el latinismo ó $\varphi \varphi$ íkıov como calco lingüístico de officium ${ }^{51}$, con el significado principalmente de cargo o función con verdaderas competencias administra-

Vid. Carlos Varela Gil, "Los deberes de los administradores públicos en Roma", Revista General de Derecho Romano, 5, 2005 [online: http://www.iustel.com] $]_{i}$ ID., El estatuto jurídico del empleado público en Derecho Romano, Madrid: Dykinson, 2007, 336 ss. La cantidad de fuentes en que se utiliza el término en este sentido es innumerable (vid. nota anterior), particularmente en relación con el officium del iudex, lo que, como debe recordarse, en la época clásica no incumbía, en principio, a ningún funcionario público, sino que era una función privada, la cual, sin embargo, siempre presentó una cierta coloración pública (vid. CANCELLI, "Nota preliminare...", cit., 243) y, como hemos señalado (vid. supra nota 42), en época postclásica, por la definitiva publificación del proceso, ya se consideró propiamente una función pública. Este es el uso del término que corresponde a los libri de officio escritos por los juristas clásicos seguramente ya a partir del siglo I (Capitón, Sabino, tal vez Labeón), pero que en el siglo III acabará convirtiéndose en un género muy extendido y de gran alcance: vid. al respecto, con detalle, Aldo DelL'ORO, I libri de officio nella giurisprudenza romana, Milano: Giuffrè, 1960.

47 D. 12.6.26.12; 32.1.65; 40.4.24; 50.15.4.5; Cod. Iust. 6.6.2, entre otros.

48 D. $1.5 .14 ; 22.5 .14 ; 50.17 .1$; Cod. Iust. 3.12 .2 etc.

49 D. $2.4 .17 ; 2.8 .7 .2 ; 6.1 .68 ; 48.3 .8 .6 ;$ Cod. Iust. 7.45 .7 , entre otros muchos. Vid. infra en el texto.

50 CervencA, "Sull'uso del termine 'officium'...", cit., sobre la base de un análisis de las fuentes contenidas en el libro I del Cod. Theod. y el libro I del Cod. Iust., en relación con los títulos de esos códigos referidos a los officia de diversos altos funcionarios, llega a la conclusión de que en el lenguaje de las constituciones imperiales este es el uso prevalente del término, si bien en las rúbricas de estos títulos se conserva prioritariamente el sentido de officium como conjunto de atribuciones del titular del cargo o función correspondiente, siguiendo la tradición de los libri de officio de los jurisconsultos clásicos. Aunque no deja de ser una investigación parcial, que solo por inducción puede ser proyectada sobre la totalidad del desarrollo legislativo del Bajo Imperio, apunta una tendencia que coincide plenamente con lo que encontramos con posterioridad en las fuentes bizantinas, que vienen a confirmar esta conclusión.

51 Sieur (Charles du Fresne) Du CANGe, Glossarium ad Scriptores Mediae et Infimae Graecitatis, vol. I, Lugduni: Apud Anissonios, Joan. Posuel \& Cl. Rigaud, 1688, 1068-1069; vid. AlEXANDER 
tivas (en oposición a dignidad o título, de carácter puramente protocolario, para el que se prefieren otros términos ${ }^{52}$ ). Asimismo es un término ampliamente utilizado en el ámbito del derecho canónico para hacer referencia a los miembros de la jerarquía eclesiástica que ostentaban funciones organizativas (v.gr., $\sigma \alpha \kappa \varepsilon \lambda \lambda \alpha \alpha_{\rho}$ posición relacionada con la ordenación sacramental ${ }^{53}$. Sin embargo, a diferencia de lo que encontramos en las fuentes romanas tardías, este término no va a ser el más importante para designar los cargos públicos, como vamos a ver ejemplificándolo a través del análisis de los términos presentes en las fuentes que aquí nos ocupan.

En efecto, en nuestras fuentes vemos el término ó $\varphi \varphi$ íkıov, en sus diversas formas, recogido seis veces en la Eisagoge, tres en el Prochiron y ocho en las Novelas de Léon. Podemos prescindir de las apariciones en el Prochiron, puesto que se trata de textos coincidentes con la Eisagoge, por lo que, en total, el término aparece usado en nuestras fuentes solo catorce veces, lo que no deja de ser un número exiguo incluso tratándose de obras que, como hemos dicho desde el comienzo, no son prevalentemente de carácter jurídico-administrativo ${ }^{54}$. Comenzaremos analizando los usos de la expresión en la Eisagoge, para luego contrastarlos con los de las Novelas de León, con el fin de examinar si existe alguna diferencia significativa en el uso del término.

\section{1. ÓФФÍKION EN LA EISAGOGE}

Las primeras apariciones de este término en la Eisagoge las encontramos en dos capítulos del título VI, referido a las competencias del gobernador provincial

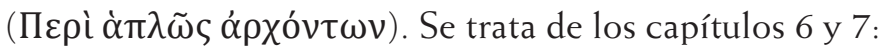

KaZHDAN, s. v. 'offices', The Oxford Dictionary of Byzantium, vol. III, New York et al.: OUP, Alexander Kazhdan (ed.), 1991, 1513.

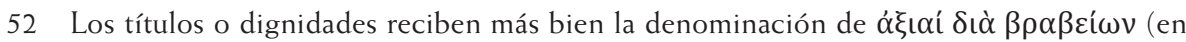

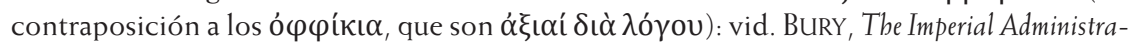
tive System..., cit., 20-23; WINKELMANN, Byzantinische Rang-und Ämterstruktur..., cit., 29-68, AleXANDer KaZHDan, s. v. 'dignities and titles', The Oxford Dictionary of Byzantium, vol. I, New York et al.: Oup, Alexander Kazhdan (ed.), 1991, 623. En el Tratado de los Oficios de

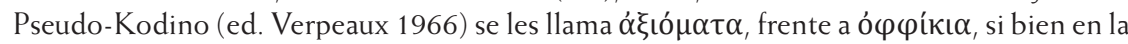
época de esta obra (siglo XIV) ya la diferencia entre unos y otros se había en gran medida difuminado (vid. VerpeauX, JeAN, "Hiérarchie et préséances sous les Paléologues", Travaux et Mémoires 1, 1965, 421-437).

53 Vid. al respecto, con detalle, JEAN DARROUZÈs, Recherches sur les ó $\varphi \varphi$ íkı $\alpha$ de l'Église byzantine, Paris: Institut Français d'Études Byzantines, 1970.

54 Aún más significativo es el hecho de que en las Novelas de Justiniano el término comparece solamente diez veces (Nov. 2 inscr.; 10 inscr.; 20 rubr./praef.; 22 epil.; 60, c. 1.1; 82 c. 1 pr.; 85 inscr.; 123 inscr.; 137 inscr.) y ninguna entre las constituciones griegas del Codex Iustinianus, frente a la enorme frecuencia con que aparece el equivalente latino officium, según hemos visto. 


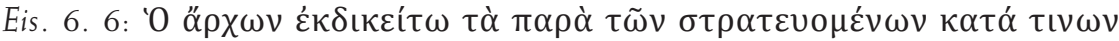

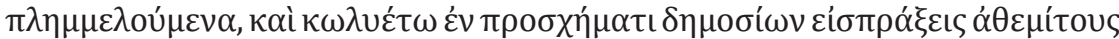

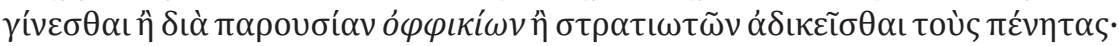

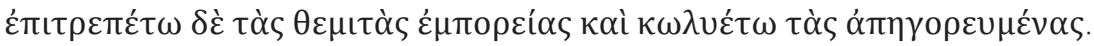

Con lenguaje moralista, el pasaje detalla las obligaciones del gobernador provincial $(\alpha \not \rho \chi \omega v)^{55}$ con relación a los provinciales, a fin de evitar que estos sufran quebrantos por las actuaciones de soldados u otras autoridades subordinadas dependientes del poder imperial, y termina con una formulación muy general referida a la permisibilidad de los negocios lícitos y la represión de los ilícitos. El texto tiene su fuente en un pasaje del Digesto procedente del libro 1 de las Opiniones de Ulpiano (D. 1.18.6) . $^{56}$.

Evidentemente, el texto de la Eisagoge es un resumen del texto de Ulpiano, con alguna variación en orden expositivo, por lo que cabe pensar (sobre todo teniendo en cuenta que se corresponde con exactitud con Bas. 6.1.40.1-5) que está tomado directamente de una adaptación escolar del texto de época de los antecessores justinianeos o los $\sigma \chi 0 \lambda \alpha \sigma \tau$ ¿кó́ inmediatamente posteriores, seguramente la Summa del Anónimo ${ }^{57}$. Lo que aquí nos interesa es precisar el significado de la expresión "ó $\varphi \varphi \iota \kappa i ́ \omega \nu$ " en este pasaje. Comparando el texto con su fuente, aun cuando la expresión de la Eisagoge es muy sintética, parece claro que en el punto que nos ocupa el referente del texto es D. 1.18.6.5, donde se habla de "adventus officiorum vel militum", por lo que, evidentemente, la

55 Vid. al respecto FRANCISCO J. ANDRÉS SANTOS, "El gobernador provincial en algunas fuentes jurídicas bizantinas", Hacia un Derecho Administrativo y Fiscal Romano II, Madrid: Dykinson, A. Fernández de Buján (dir.), G. Gerez Kraemer (ed.), 2013, 39-47; ID., "'Apxov en algunas fuentes jurídicas bizantinas", en Ianua Classicorum. Temas y formas del Mundo Clásico, vol. III, Madrid: SEEC, 2015, 119-126 (con más referencias).

56 Illicitas exactiones et violentia factas, et extortas metu venditiones et cautiones vel sine pretii numeratione probibeat praeses provinciae. item ne quis iniquum lucrum aut damnum sentiat, praeses provinciae provideat.

1. Veritas rerum erroribus gestarum non vitiatur: et ideo praeses provinciae id sequatur quod convenit eum ex fide eorum quae probabuntur.

2. Ne potentiores viri bumiliores iniuriis adficiant neve defensores eorum calumniosis criminibus insectentur innocentes, ad religionem praesidis provinciae pertinet.

3. Illicita ministeria sub praetextu adiuvantium militares viros ad concutiendos bomines procedentia probibere et deprebensa coercere praeses provinciae curet, et sub specie tributorum illicitas exactiones fieri probibeat.

4. Neque licita negotiatione aliquos probiberi neque probibita exerceri neque innocentibus poenas irrogari ad sollicitudinem suam praeses provinciae revocet.

5. Ne tenuis vitae homines sub praetextu adventus officiorum vel militum, lumine unico vel brevi suppellectili ad aliorum usus translatis, iniuriis vexentur, praeses provinciae providebit.

6. Ne quid sub nomine militum, quod ad utilitates eorum in commune non pertinet, a quibusdam propria sibi commoda inique vindicantibus committatur, praeses provinciae provideat. Vid. al respecto ОTTO LENEL, Palingenesia iuris civilis, vol. II, Leipzig: B. Tauchnitz, 1889 (reimpr. Graz: Akademische Druck- und Verlagsanstalt, 1960), 1001-1002 (Ulp. 2296).

57 Vid. al respecto, últimamente, LOKIN y VAN BOCHOVE, "Compilazione - educazione purificazione...", cit., 128-129. 
expresión griega es un mero calco lingüístico del officiorum latino (es decir, no ha sido exbelenizado ${ }^{58}$ ni por los autores de la Eisagoge ni por los de los Basílicos). La disposición paralela de ambos términos, officia y milites, está vinculada, obvio es decirlo, con la distinción entre funcionarios civiles y militares (militia palatina o armata, militia civilis o militaris $)^{59}$-aunque en algunas fuentes se llame a todos los servidores públicos milites ${ }^{60}$ o $\sigma \tau \rho \alpha \tau \iota \tilde{\omega} \tau \alpha \iota^{61}$ y en ocasiones se hable de dos diferentes officia, uno civil y otro militar ${ }^{62}$. Por lo tanto, en este texto la expresión alude al conjunto de funcionarios (civiles) o subordinados que, al servicio del poder público en la provincia, puedan entrar en contacto con los provinciales dando lugar a abusos, especialmente sobre personas de reducidos recursos. El uso de la expresión coincide, pues, con la tendencia general que hemos señalado anteriormente, en el seno de la legislación postclásica, aun cuando el texto proceda de una fuente clásica.

En directa conexión con el texto anterior se encuentra este otro, que también versa sobre las competencias del gobernador provincial:

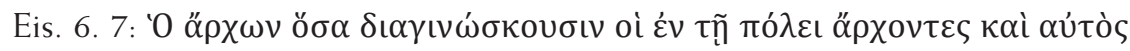

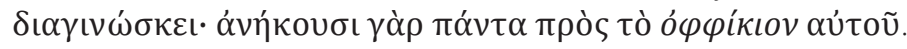

Este pasaje procede también del título 18 del libro primero del Digesto, pero esta vez se trata de una refundición y síntesis de dos fragmentos de ese título, el 10 y el $11^{[63]}$. El texto de Eisagoge está fuertemente abreviado y, en su laconismo, resulta difícilmente comprensible si no se tiene en cuenta el referente justinianeo. Probablemente el autor de la Eisagoge comprimió una versión más extensa de los pasajes tomada de un index del Digesto ${ }^{64}$, con un resultado excesivamente escueto. En todo caso, con respecto a lo que aquí nos interesa, el texto (al igual que los Basílicos) conserva el latinismo ó $\varphi \varphi$ íkıov para traducir el officium original. Pero en este caso, a pesar de encontrarse el término usado en inmediata conexión con el anterior, sin embargo, el significado difiere,

58 Vid. supra en el texto.

59 Cod. Theod. 6.24.9; 7.1.6; 7.22.12; 8.7.16.1; 8.4.28; Nov. Valent. 2.2.3; Cod. Iust. 9.3.32; $11.68 .3 ; 12.19 .8 ; 12.33 .4$

60 Officiorum omnium milites: Lact. 31; Symn. relat. 23.8/11.

61 Lyd. de mag. 3.30.

62 Caso del dux Arabiae en Not. Dign. 37.36, 4.

63 D. 1.18 .10 (Hermog. 2 iuris epit.): Ex omnibus causis, de quibus vel praefectus urbi vel praefectus praetorio itemque consules et praetores ceterique Romae cognoscunt, correctorum et praesidum provinciarum est notio.

D. 1.18.11 (Marci. 3 inst.): Omnia enim provincialia desideria, quae Romae varios iudices babent, ad officium praesidum pertinent.

64 En los Basílicos, en cambio, se recoge una versión de los textos más apegada al original: Bas.

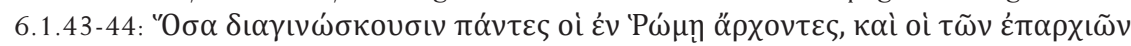

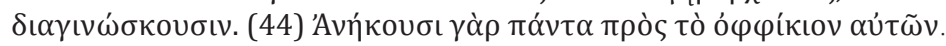


puesto que aquí no puede hacer referencia al staff de funcionarios que están al servicio del gobernador provincial, sino que alude más bien al ámbito de competencias del mismo, en este caso en el ámbito judicial. No obstante, esto solo se desprende claramente mediante la lectura del referente justinianeo del pasaje, ya que ahí, en el fragmento 11, se dice explícitamente cuál es el sujeto de la frase que tiene "ad officium praesidum" por complemento, y este es "desideria" (aquí con el sentido de "petición", "reclamación", "demanda"65), lo cual, evidentemente, nada tiene que ver con un conjunto de funcionarios. De la lectura simple de la Eisagoge, en cambio, esta conclusión no puede extraerse de manera tan clara, puesto que la frase, por su brevedad, resulta ambigua, y tanto podría entenderse en ella ó $\varphi \varphi$ íkı v como conjunto de competencias como, asimismo, como cuerpo de funcionarios al servicio del gobernador. Resulta curioso, con todo, que el autor de la Eisagoge, que evidentemente ha intervenido sobre el texto recibido de la tradición escolar ${ }^{66}$, no haya exbelenizado el término ni haya tratado de deshacer la ambigüedad que ya venía arrastrando el texto griego que le sirve de base, lo que constituye una prueba de que, en su época, ambos significados de "ó $\varphi \varphi$ íkıov" se entendían perfectamente compatibles, como en su paralelo latino.

El tercer testimonio del término en la Eisagoge lo encontramos en el siguiente pasaje:

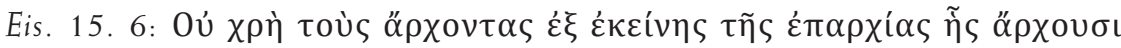

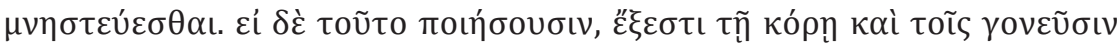

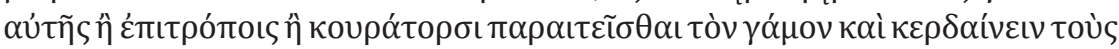

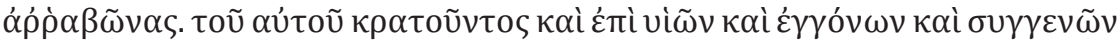

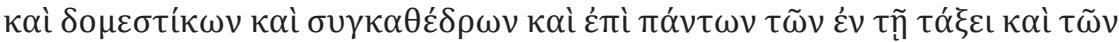

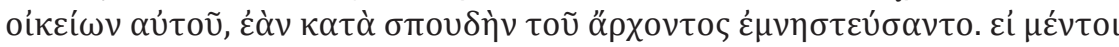

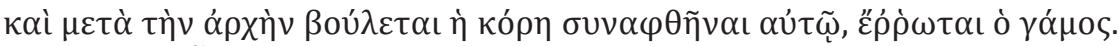

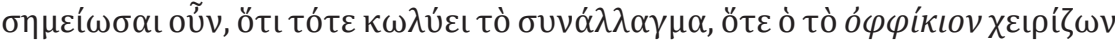

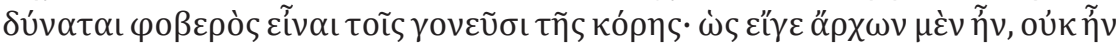

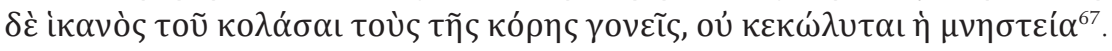

Vid. Heumann y SeCKel, Handlexikon..., cit., 140 (s. v. „desiderium”).

66 Puesto que, como vemos en el texto de los Basílicos (vid. nota 55), en la primera versión se seguía haciendo referencia a los magistrados "de Roma", expresión anacrónica que el autor de la Eisagoge, juiciosamente, ha sustituido por "de la Ciudad (scil. Constantinopla)" ( $\dot{v} v \tau \tilde{n} \pi$ Tó $\lambda \varepsilon \iota)$, mientras fue conservada, sorprendentemente, por los compiladores de los Basilicos.

67 El texto coincide literalmente, salvo leves diferencias (vid. infra en el texto), con Proch. 2.8 y también el Hexabiblos de Armenópulo (Hexab. 4.2.9) lo recoge en los mismos términos que este último; Bas. 28.1.20, en cambio, recoge solo la primera parte del pasaje (hasta

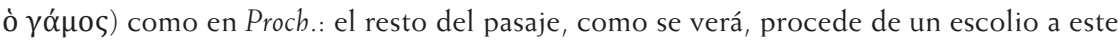
texto de Bas., procedente del index del Codex de Teleleo. 
El pasaje, a diferencia de los anteriores, no se encuentra en el título específico referido a las funciones de los gobernadores provinciales, sino en el XV,

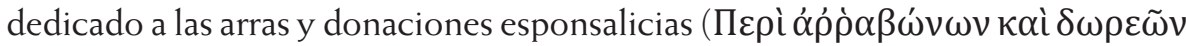
$\mu \nu \eta \sigma \tau \varepsilon i ́ \alpha \varsigma)$. No obstante, también su contenido está vinculado a la regulación del ámbito de poderes del gobernador provincial, por lo que nada hubiera impedido que se hubiera ubicado también en el título VI, salvo por el hecho de que el autor de la Eisagoge ha ido siguiendo un determinado orden en la selección de los textos sin alterar demasiado el de las fuentes que le sirven de referencia, y este título de la obra está compuesto fundamentalmente sobre textos del libro $\mathrm{V}$ del Codex Iustinianus, que comienza tratando justamente la materia de sponsalibus et arrbis sponsalitiis. El título 2 de ese libro versa en concreto sobre la regulación de las arras esposalicias proporcionadas por el gobernador provincial o sus subordinados (Si rector provinciae vel ad eum pertinentes sponsalia dederint), que es de donde procede el texto que nos ocupa, al menos en su primera parte. En efecto, las primeras líneas del texto, desde el comienzo hasta "ò yó $\mu o \varsigma^{\prime \prime}$ corresponden a una traducción libre y abreviada del texto de Cod. Iust. 5.2.1, una constitución del año 380 dada por los emperadores Graciano, Valentiniano y Teodosio I ${ }^{68}$.

En esta parte del pasaje de Eis. no encontramos aún la expresión que aquí nos interesa en primer término (ó $\varphi \varphi$ íkıov), pero sí alguna otra a la que haremos alusión más adelante. El término que nos ocupa solo comparece en la segunda mitad del texto, a partir de $\sigma \eta \mu \varepsilon i ́ \omega \sigma \alpha \mathrm{t}$. Sin embargo, este bloque no encuentra ninguna referencia explícita en las fuentes justinianeas, y el propio inicio del inciso $(\sigma \eta \mu \varepsilon i ́ \omega \sigma \alpha \mathrm{l})$ nos viene ya a indicar que se trata de una explicación o añadido al texto anterior, que en los Basílicos se identifica con un escolio de Taleleo ${ }^{69}$ (es decir, un pasaje procedente del index del Codex Iustinianus de este antecessor de época justinianea ${ }^{70}$ ), que aclara que lo previsto

68 Si quis in potestate publica positus atque honore administrandarum provinciarum, qui parentibus aut tutoribus aut curatoribus aut ipsis quae matrimonium contracturae sunt potest esse terribilis, arras sponcalicias dederit, inbemus, ut deinceps, sive parentes sive eadem mutaverint voluntatem, non modo iuris laqueis liberentur poenaedue statutae expertes sint, sed extrinsecus data pignora lucrativa babeant, si ea non putent esse reddenda.

1. Quod ita late patere volumus, ut non solum circa administrantes, sed et circa administrantium filios nepotes ac propinquos, participes (id est consiliarios), domesticosque locum babeat, quibus tamen administrator operam dederit.

2. Impleri autem id postea matrimonium non vetamus, quod tempore potestatis ob eas personas, de quibus locuti sumus, arris fuerat obligatum, si sponsarum consensus accedat.

Vid. asimismo Cod. Theod. 3.6 .1 (= brev. 3.6.1), que omite, sin embargo, significativamente, "id est consiliarios" del texto del Cod. Iust., lo que deja bien claro que el autor del texto original de Eis. (probablemente Taleleo) no tuvo en cuenta el texto del Teodosiano.

69 Schol. 2 in Bas. 28.1.20 (ed. Scheltema, Basilicorum Libri LX. Series B: Scholia, vol. V, Groningen et al.: J. B. Wolters, Hermann J. Scheltema, Nicolaas van der Wal y Douwe Holwerda (eds.), 1988, 1803).

70 Vid. al respecto, últimamente, LOKIN, y VAN BOCHOVE, "Compilazione - educazione purificazione...", cit., 131-132. 
en el párrafo anterior (es decir, la posibilidad que tiene la mujer que hubiera contraído esponsales con el gobernador de la provincia en que vive, así como los padres o tutores de ella si esta fuera menor, de retractarse y resolver el contrato sin asumir ninguna responsabilidad, y quedándose con las arras que les hubieran sido entregadas o reclamando la devolución de las que hubieran dado a su vez) solo es aplicable en el supuesto de que, efectivamente, el gobernador provincial estuviera en condiciones de intimidar o causar temor a los padres, y no, en cambio, si dicha condición no se cumpliera, en cuyo caso el contrato debe considerarse válido y vinculante. Habría algunas cuestiones exegéticas que discutir en relación con este texto, pero en las cuales no podemos entrar en este lugar ${ }^{71}$. Lo que nos interesa en este punto es que aquí sí

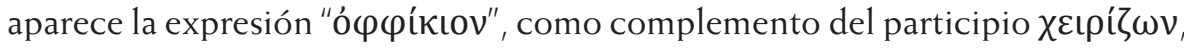
formando un sintagma que solo encontramos una vez más en la obra (Eis. 8.13), pero esta vez no con el sustantivo ó $\varphi \varphi$ íкıov, sino $\varphi \rho o ́ v \tau \iota \sigma \mu \alpha$, lo que nos debería llevar a analizar si este último término presenta idéntico significado que el primero o no. Pero esta es una cuestión en la que no podemos entrar ahora. En cualquier caso, tanto en uno como en otro supuesto evidentemente el complemento del verbo $\chi \varepsilon i \rho i ́ \zeta \omega$ no alude a ningún conjunto de personas, sino que designa una posición jurídica, un conjunto de atribuciones o competencias, en este caso de Eis. 15.6, obviamente del gobernador provincial: "ò

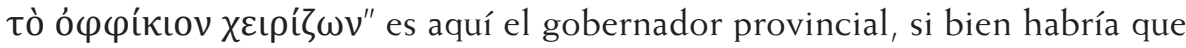
entender, interpretando el texto de este párrafo en conexión con la primera

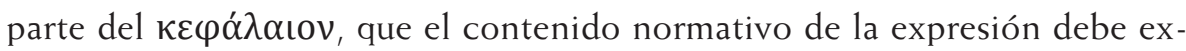
tenderse también a las otras personas a las que se vetan los esponsales con las mujeres provinciales, es decir, los parientes del gobernador y sus asesores y los funcionarios a su servicio, pero esto es una cuestión exegética que en este lugar no nos compete. Lo cierto es que aquí ó $\varphi \varphi$ íkıov vuelve a presentar, al igual que en el anterior caso de Eis. 6.7, el significado de función o deber de la persona que ostenta un cargo, es decir, el primero de los significados de officium que hemos señalado más arriba.

Lo que resulta llamativo es que en esta parte del texto el autor use justamente la expresión "ó $\varphi \varphi$ íkıov". El autor original del texto es el antecessor Taleleo, y a él parece natural atribuirle fácilmente un latinismo como este, pero, en todo caso, resulta llamativo, por un lado, que el autor de la Eisagoge no haya exbelenizado el término (es decir, que no haya buscado un vocablo griego más comprensible para el helenohablante en general), y, por otro, que el propio Taleleo haya utilizado este latinismo en vez de emplear un término griego más común. Para la primera cuestión la respuesta más obvia es que el autor de la Eisagoge se limitó a conservar el texto literal que encontró en su fuente originaria,

71 V.gr., si la excepción ahí contemplada solo se refiere a los padres de la prometida, o también pueden incluirse las otras personas mencionadas (curadores, tutores, incluso la propia prometida). 
presumiblemente el index de Taleleo, sin introducir alteraciones más que cuando fuese estrictamente necesario, y en este caso no se vería así, lo que implica que en su tiempo la expresión "ó $\varphi \varphi$ íкıov" aún resultaba comprensible en este sentido. Ello parece confirmado por el hecho de que en el texto de la Eisagoge

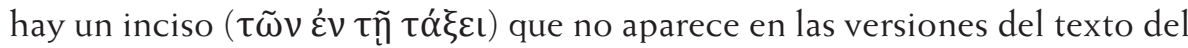
Prochiron y los Basílicos ${ }^{72}$, lo que solo se podría explicar o por una intervención específica del autor de la Eisagoge en este texto, o por una alteración textual por los autores del Procbiron ${ }^{73}$, o bien por un defecto de transmisión textual del texto de Taleleo a los autores del Procbiron (y, eventualmente, los Basílicos). Pero si se tiene en cuenta que el inciso que aparece en la Eisagoge parece ser una traducción libre del sintagma "quibus tamen administator operam dedit" del original del Codex Iustinianus, las dos últimas hipótesis aparecen poco probables, porque el texto de Eis. 15.6 resulta más cercano al original latino, por lo que no cabe pensar en una intervención de su autor en tal sentido, y tampoco resulta comprensible por qué el autor del Prochiron tendría ninguna necesidad de suprimir esa expresión, que completa razonablemente el texto anterior y es conforme con el original justinianeo. Por tanto, la hipótesis más probable es que esa expresión desapareció del Prochiron (y, a su vez, de los Basílicos) simplemente por un error de transmisión textual que pasó inadvertido a los compiladores $^{74}$, y que el texto original de Taleleo era similar al de la Eisagoge. Esto nos puede dar una clave explicativa también para la segunda duda que nos plantábamos: por qué Taleleo emplea un latinismo como ó $\varphi \varphi$ íкı tiene ninguna necesidad de usarla en un pasaje que no traduce directamente ninguna fuente latina con esa palabra, sino que escribe un texto exegético ex novo. Y una razón puede ser, precisamente, que, como veremos, uno de los

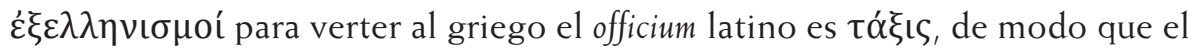
uso de la palabra "ó $\varphi \varphi$ íкıov" aquí podría haber tenido un valor estilístico a fin de evitar la repetición de los términos. De todos modos, los significados

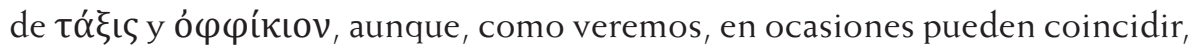
aquí, en cambio, son divergentes.

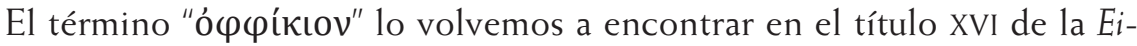

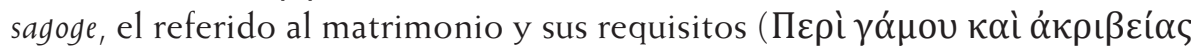

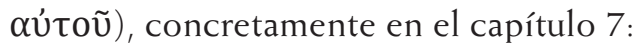

72 Vid. supra nota 65

73 Considerando que seguramente el texto de Bas. 28.1.20 está tomado de Proch. 2.8, y no al revés, o bien proceden de una fuente común leída independientemente por los autores de una u otra compilación, pero eso parece improbable, por lo que se explica en el texto.

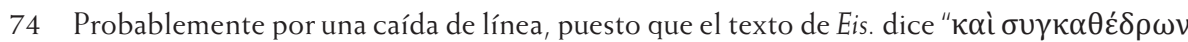

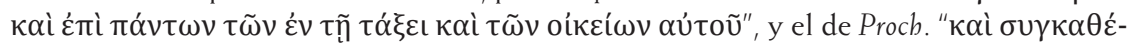

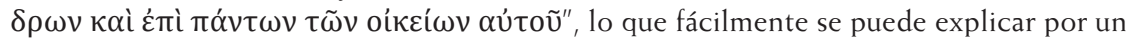
error del copista, transmitido a los sucesivos textos. 


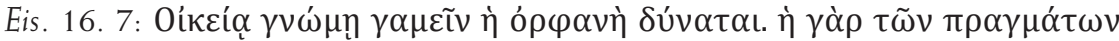

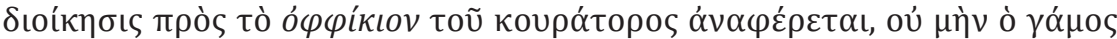
$\alpha u ̛ \tau \tilde{\eta}$.

El texto aparece recogido en los mismos términos en Proch. 4.11 y, con ligeras variantes, en Bas. 28.4.12 $2^{[75]}$, y constituye una traducción libre del texto de D. 23.2.20, procedente de un liber singularis ad orationem divorum Marci Antonini et Commodi de Paulo ${ }^{76}$.

Aquí existen pocas dudas respecto al significado de ó $\varphi \varphi$ íkıov, puesto que se trata simplemente de un calco lingüístico del original latino officium curatoris utilizado en la constitución de los emperadores del siglo III $^{77}$. Nos encontramos, por tanto, ante un uso distinto de los anteriores, puesto que ya no nos hallamos ante un officium publicum sino privatum, es decir, un deber propio de un cargo en la esfera privada, no funcionarial (aunque se trate, como hemos dicho más arriba ${ }^{78}$, de funciones que, aun siendo privadas, se entiende que tienen una cierta dimensión pública, como es la del curator), lo que nos indica que en el lenguaje de los antecessores que hicieron la versión griega del Digesto (aquí no podemos determinar con exactitud cuál pudo ser la obra concreta de la que el autor de la Eisagoge pudo haber tomado el texto) el latinismo ó $\varphi \varphi$ íкıov presenta aparentemente los mismos significados que su homólogo latino.

Las dos últimas apariciones de este término en la Eisagoge las encontramos

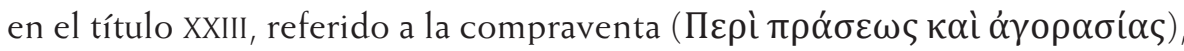
lo que no deja de ser llamativo, tratándose de un título de fuerte contenido privatístico. Son dos pasajes seguidos, los capítulos 17 y 18 , que se encuentran íntimamente relacionados:

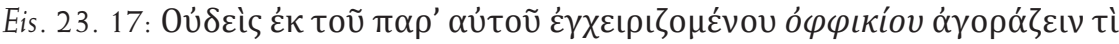

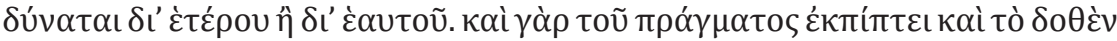

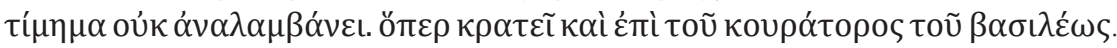

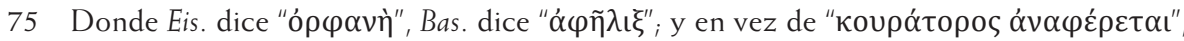

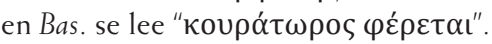

76 Sciendum est ad officium curatoris non pertinere, nubat pupilla an non, quia officium eius in administratione negotiorum constat: et ita Severus et Antoninus rescripserunt in baec verba: 'Ad officium curatoris administratio pupillae pertinet: nubere autem pupilla suo arbitrio potest'. Dig. intitula el pasaje 'ad orationem divi Severi et Commodi', pero se trata obviamente de un error de transmisión textual: vid. Dig. ed. minor ad b. l. y LENEL, Palingenesia..., cit., vol. I, 1145 (Paul. 1066).

77 El sintagma aparece en el Digesto, fuera de este texto, solamente tres veces: Clem. D. 23.3.61.1, Ulp. D. 27.5.1.7 y Paul. D. 39.2.46 pr. (en este caso referido al curator rei publicae, que sí es un officium publicum). En cualquier caso, la curatela, como la tutela, eran consideradas como officia necessaria (y, de ahí, munera): vid. CANCELLI, "Nota preliminare...", cit., 243.

Vid. supra en el texto (apartado 2) y notas 42 y 44 . 


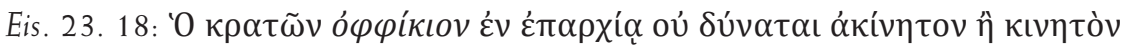

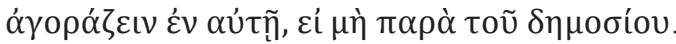

Ambos pasajes, aunque se encuentren ubicados en un título referido a cuestiones de derecho privado, tienen también una dimensión público-administrativa, porque vuelven a hablar de funcionarios imperiales, en particular los destacados en provincias, que son justamente aquellos a los que la Eisagoge presta una atención especial ${ }^{79}$.

El primero de ellos, recogido también, con algunas variaciones, en Proch. $14.2^{[80]}$ y en Bas. 19.1.46 $6^{[81]}$, corresponde a un pasaje del liber singularis de delatoribus de Marciano ${ }^{82}$, recogido en D. 18.1.46 ${ }^{[83]}$. El pasaje se incluye en el Digesto en el marco de las compras perpersonam interpositam, y lo que se dice es que no resulta admisible que alguien que tiene el deber (officium) de administrar una cosa la compre para sí, aunque sea utilizando los servicios de un tercero. En principio, la expresión es muy general, y officium puede hacer referencia a toda clase de función de ocuparse de bienes ajenos, sea un sujeto privado o un funcionario, es decir, ya se trate de un officium publicum o privatum ${ }^{84}$. La palingenesia del pasaje de Marciano tampoco nos aclara si se trataba en su origen tan solo de los titulares de un officium publicum, o bien afectaba también

79 Vid. Signes Codoñer y ANDrés SAntos, La Introducción al Derecho (Eisagoge)..., cit., 24.

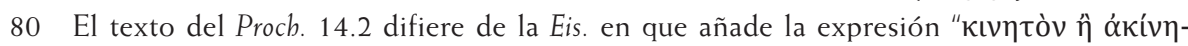

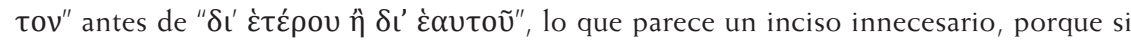
se dice sin más que no es lícito al administrador comprar bienes que están sujetos a su administración, es evidente que se refiere tanto a bienes como a inmuebles: la aclaración, que tiene visos de glosa introducida por el autor del texto manejado por el compilador del Proch., probablemente está pensada para dejar claro que no es el mismo supuesto que el de la prohibición de adquisición de inmuebles que recaía sobre los gobernadores provinciales en el territorio de su administración: en todo caso, vid. infra en el texto. Además, el

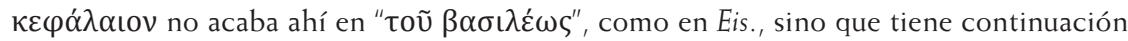
(vid. infra nota 81), probablemente debido a que esta obra ha fundido la traducción del pasaje correspondiente del Dig. con la de D. 18.1.62 pr., mientras que Eis. las mantiene separadas: vid. a continuación en el texto.

81 En la ed. de Heimbach (Karl Wilhelm ERnST HeimbaCH, Basilicorum libri LX, vol. II, Lipsiae, 1940, 265) es Bas. 19.1.44.2, reconstruido a partir de Hexab. 3.3.6. La ed. de Scheltema (Basilicorum Libri LX. Series A: Textus, vol. III, Groningen et al.: J. B. Wolters, Hermann J. Scheltema, Nicolaas van der Wal, Douwe Holwerda (eds.), 1960, 920) hace una lectura

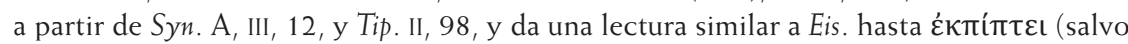

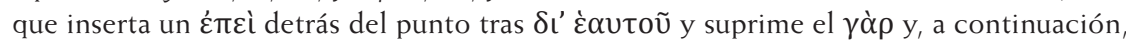

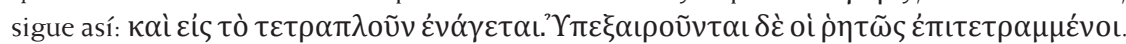

82 Vid. Lenel, Palingenesia..., cit., vol. I, 642 (Marci. 10).

83 Non licet ex officio, quod administrat quis, emere quid vel per se vel per aliam personam: alioquin non tantum rem amittit, sed et in quadruplum convenitur secundum constitutionem Severi et Antonini: et boc ad procuratorem quoque Caesaris pertinet. sed boc ita se babet, nisi specialiter quibusdam boc concessum est.

84 Una referencia común a ambos supuestos la ve CANCELLI, "Saggio sul concetto di officium...", cit., 381 . 
a cualesquiera otros a quienes tradicionalmente se atribuía un officium también en la esfera privada. En todo caso, la referencia a la constitución de Septimio Severo y Caracalla hace pensar que la expresión es omnicomprensiva, puesto que esta al parecer también prohibía explícitamente la compra por el tutor de bienes del pupilo incluso per interpositam personam ${ }^{85}$. La explícita mención final del procurator Caesaris confirma la hipótesis de que, en principio, el texto piensa más bien en los officia de carácter privado, como es el caso típico del procurator $^{86}$, pero no excluye los de carácter público ${ }^{87}$ (para los cuales, no obstante, hay normas específicas, como vamos a ver en seguida), y por eso se siente en la obligación de aclarar que el procurator Caesaris es un caso igualmente contemplado en el rescripto, aunque se trate, obviamente, de un alto funcionario encargado de las finanzas imperiales en las provincias ${ }^{88}$. El texto de Eisagoge recoge la disposición del Digesto de manera bastante literal, si bien en el último inciso, referido al procurator Caesaris, el texto de Eisagoge habla de "кoupóctopos

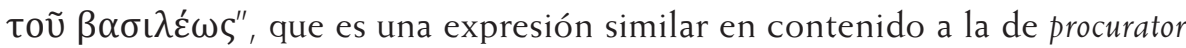
Caesaris, pero mucho menos común ${ }^{89}$ y un anacronismo evidente en la época de redacción de la obra ${ }^{90}$; además, el texto de Eisagoge no recoge el último inciso del pasaje del Digesto, que admite como excepción a esta regla de la imposibilidad de comprar cosas comprendidas en el ámbito de administración del cargo de procurator Caesaris el supuesto de que el emperador le hubiera autorizado a hacerlo: en la norma de Eis. 23.17 la regla se presenta, por tanto,

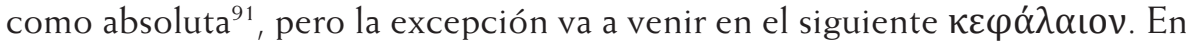

85 Ulp. D. 26.8.5.3 (Ulp. 40 ad Sab.): Sed si per interpositam personam rem pupilli emerit, in ea causa est, ut emptio nullius momenti sit, quia non bona fide videtur rem gessisse: et ita est rescriptum a divo Severo et Antonino. El parágrafo anterior (eod. 5.2) indica, significativamente, con carácter general, que el tutor "emptoris et venditoris officio fungi non potest". En sentido similar de prohibición de un abuso del cargo tutelar, la Nov. Iust. 120.5.1 prohíbe a los ecónomos y administradores de casas de huérfanos que adquieran arrendamientos, enfiteusis o hipotecas sobre bienes pertenecientes a esas mismas casas. Sobre la prohibición a funcionarios de llevar a cabo contratos prohibidos para ellos per interpositam personam, vid. Hermog. D. 49.14.46.2; Cod. Iust. 1.53.1.3; Gordian. Cod. Iust. 4.2.3.

86 Vid. supra nota 34

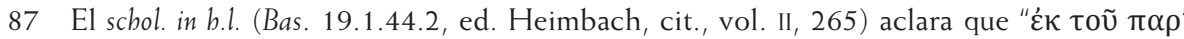

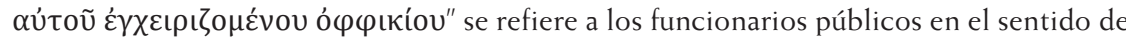
Bas. 57.1.18.

88 Sobre el procurator Caesaris, vid. D. $1.19 ; 2.15 .8 .19 ; 4.6 .35 .2 ; 29.2 .25 .2 ; 49.1 .4 .1$; eod. $23.1 ; 49.14 .47 .1 ; 50.6 .6 .10$; procurator principis: D. 1.16 .9 pr.; 4.6.32; procurator imperialis: D. 49.14.50

89 En el Digesto solo aparece dos veces, en Callist. D. 1.19.3 pr. y Ulp. 49.15.5 pr. Proch.

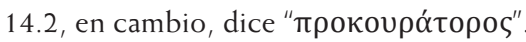

90 E incluso probablemente en la época de elaboración del Digesto, como demuestra el hecho de que es una figura que no se menciona ni en las constituciones justinianeas del Codex Iustinianus ni en las Novellae.

91 En Proch., en cambio, se introduce en el capítulo correspondiente (14.2) la salvedad "عí $\mu$ 门̀

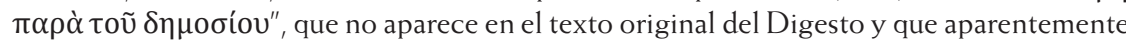


cualquier caso, por lo que aquí nos interesa, parece obvio que el significado que el autor de la Eisagoge maneja en este texto para ó $\varphi \varphi$ ́́́кı v es el primero de los que hemos indicado más arriba, es decir, el de deber en general de alguien que tiene que velar por intereses ajenos, sean estos intereses de carácter público o privado, es decir, un sentido idéntico al del viejo officium romano en

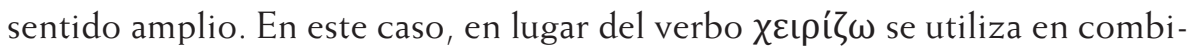
nación con la forma compuesta $\varepsilon \gamma \chi \varepsilon\llcorner\rho i ́ \zeta \omega$, una variante que solo aparece en este pasaje en toda la obra.

Más específico es, en cambio, el significado que presenta la expresión en el segundo pasaje citado, que complementa al anterior. En él se hace una traducción abreviada y adaptada de D. 18.1 .62 pr. (Modest. 1. 5 reg.) ${ }^{92}$. En este pasaje se prohíbe al funcionario provincial, sea civil o militar (agit vel militat), que lleve a cabo adquisiciones de inmuebles en el territorio provincial en que presta servicio, con el fin de evitar la posibilidad de exacciones ilícitas y abusos sobre los habitantes de la provincia aprovechando el carácter público o la fuerza militar de quien representa al Estado allí (y no olvidemos que se trata ya de un Estado claramente autoritario en el momento de redacción del texto original). Esta norma se repite en otros pasajes de las fuentes ${ }^{93}$, si bien con cierto carácter contradictorio que en el pasaje de Eisagoge se resuelve: en efecto, en las fuentes justinianeas se dice en unos casos, como en este texto de Modestino, que la prohibición de adquirir se refiere a los inmuebles ${ }^{94}$, mientras que en otros parece hacer referencia a toda clase de bienes, muebles e inmuebles (lo cual no deja de ser, ciertamente, excesivo) ${ }^{95}$. El texto de Eisagoge

se corresponde más bien con el contenido de Eis. 23.18 (vid. en el texto), lo que hace suponer, por tanto, que el autor del Proch. ha hecho una refundición de materiales que en Eis. aparecen separados; pero lo hace de manera muy imperfecta, porque parte del contenido de Eis. queda sin transcribir, y además refiere la excepción de la imposibilidad

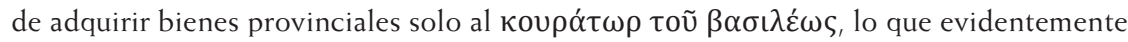
nada tiene que ver con lo establecido en el Digesto, por lo que no cabría excluir, o bien una redacción apresurada del capítulo en el Procb. (lo que no es descartable, dado que el mismo tenor incorrecto se transmite en Hexab. 3.3.6), o bien un error de transmisión manuscrita. En cambio, Bas. 19.1.46 da una versión más completa de D. 18.1.46; sin embargo, Hexab. 3.3.6 añade el inciso de Proch. 14.2, así como otro inciso final, que no

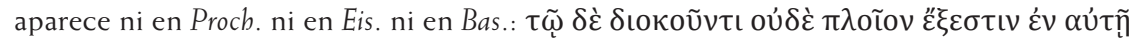

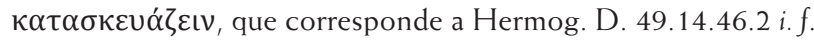

92 Qui officii causa in provincia agit vel militat, praedia comparare in eadem provincia non potest, praeterquam si paterna eius a fisco distrabantur. Vid. LeNEL, Palingenesia..., cit., vol. I, 735 (Mod. 215).

93 V.gr., HeRmoG. D. 49.14.46.2; Marci. D. 46.16 .9 pr.; Cod. Iust. 1.53.1; GORDian. Cod. Iust. 4.2.3 prohíbe a los funcionarios en provincias hacer préstamos con interés a los provinciales.

94 Así también en MARCI. D. 46.16 .9 pr., referido únicamente a los militares.

95 Así en Hermog. D. 49.14.46.2 se prohíbe al gobernador y demás funcionarios provinciales toda adquisición en territorio provincial, quedando el contrato sujeto a la posibilidad de resolución y perdiendo el adquirente el precio a favor del fisco; en Cod. Iust. 1.53.1 pr. se prohíbe (y además con efecto retroactivo) a los funcionarios que prestan servicio en 
es taxativo, y establece claramente que la prohibición se refiere a todos los

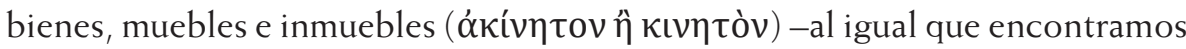
en Proch. 14.2-, en aplicación de una constitución de Justiniano del año 528

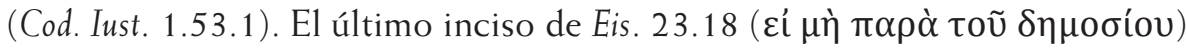
trata de traducir el final del texto de Modestino, pero lo hace de manera muy imperfecta, puesto que da la sensación de que cualquier bien que fuera vendido por el fisco podría ser adquirido por el funcionario, con lo que el espíritu de la norma quedaría hasta cierto punto diluido, ya que los mismos funcionarios que manejaran el fisco podrían adquirir los bienes en cuestión, con lo que la finalidad de prevenir abusos sobre los administrados podría quedar desvirtuada. El texto original de Modestino, en cambio, establece una limitación muy seria a esta excepción, puesto que reduce los bienes que pueden ser comprados por los funcionarios a partir del fisco únicamente a los bienes paternos del funcionario, es decir, bienes que, por algún motivo, hubieran sido confiscados al padre del funcionario (o a su patrimonio) y vendidos en pública subasta, en cuyo caso sí se admitiría la compra por parte de este por razones de respeto a la pietas tradicional y el deseo de fomentar la conservación de los patrimonios familiares (es decir, un caso en el que no cabe la posibilidad de extorsión del funcionario sobre los provinciales, puesto que se trataría de bienes hasta cierto punto ya de titularidad anterior del funcionario en cuestión). El texto de Hexab. 3.3.6, en cambio, contiene el adjetivo sustantivado $\pi \alpha \tau \rho \tilde{\omega}$ ov , que viene a traducir los (bona) paterna del original del Digesto. Cabría pensar, por esto, que tal vez ha habido una mala transmisión del texto de Eis. 23.18, pero esto es dudoso, dada la coincidencia en este punto con el texto de Proch. 14.2, por lo que tal vez habría que considerar la existencia de una redacción apresurada de estos compendios y una probable influencia de uno en otro (más probable, a nuestro juicio, de Proch. sobre Eis. que viceversa, aunque ello es cuestión sumamente controvertida ${ }^{96}$ ).

En cualquier caso, respecto a lo que a nosotros nos interesa aquí, es decir, el uso del término "ó $\varphi \varphi$ íkı rencia a la persona que ejerce un officium, es decir, un conjunto de atribuciones que corresponden a un cargo público, en sentido amplio, lo que en el original de Modestino se dice de una forma mucho más compleja y rebuscada, aunque

Constantinopla la compra de toda clase de bienes muebles o inmuebles, salvo que reciban permiso; en el $§ 2$ se extiende esta disposición a los gobernadores provinciales sobre bienes situados en su provincia, salvo lo necesario para su sustento, y en el $§ 3$ se amplía esto también los domésticos y consejeros de los anteriores. Esta es una constitución de Justiniano del año 528, lo que indica que las disposiciones anteriores que pudieran disponer algo en el mismo sentido, o no se consideraban vigentes, o carecían de eficacia. En todo caso, no es descartable que se trate de una innovación justinianea, porque el texto de Hermogeniano citado con anterioridad puede interpretarse fácilmente como referido tan solo a los inmuebles.

Vid. supra nota 6. 
también más precisa ("qui officii causa in provincia agit vel militat"). Se trata, por tanto, nuevamente del uso del término en el sentido estricto de officium publicum para designar un cargo administrativo, como hemos encontrado ya en Eis. 6.7 y 15.6. Ello lo sabemos no solo a través de la lectura del referente justinianeo que hemos visto, sino también por el hecho de ir el sustantivo acompañado de

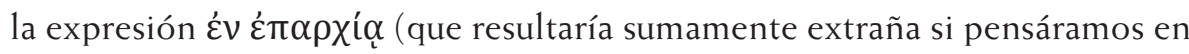

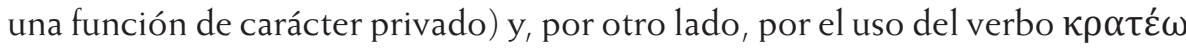
para formar el sintagma, un verbo que está siempre relacionado con el ejercicio del poder o con la validez de las normas ${ }^{97}$. Resulta sorprendente, no obstante, que en este pasaje, por un lado, se introduzca la precisión, no existente en el original del Digesto, en el sentido de que la prohibición de adquirir se refiere a toda clase bienes, muebles e inmuebles, siguiendo la reforma introducida

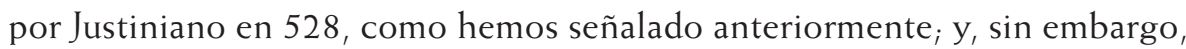
por otro lado, el alcance de la norma se limite, como en el original clásico, a

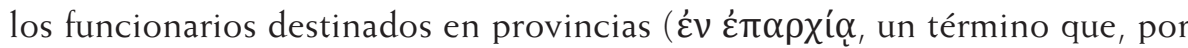
otra parte, también suscita cierta sorpresa), cuando la norma justinianea (Cod. Iust. 1.53 .1 pr.) había ampliado el campo de acción de la regla también a los funcionarios destinados en Constantinopla. Ello demuestra, una vez más, un cierto descuido en la redacción del capítulo por parte del autor de la Eisagoge, que probablemente se limitó a transcribir con rapidez el texto que encontró en el correspondiente index del Digesto.

\section{2. ÓФФÍKION EN LAS NOVELAS DE LEÓN VI}

Veamos ahora si el análisis anterior se confirma o se altera a la vista de las apariciones del término en las Novelas de León VI.

Ahí encontramos la palabra mencionada un total de ocho veces en la colección oficial de 113 Novelas de este emperador ${ }^{98}$ (Nov. Leon. 1; 18; 19; 20; 21 ; $22 ; 26 ; 28)$, curiosamente todas ellas en forma de genitivo plural (ó $\varphi \varphi$ íkíc $\omega$ ), lo cual ya nos da una primera pista sobre su significado real.

En efecto, todas las apariciones del término en la obra se dan en las inscriptiones de las diversas Novelas en que se menciona, y todas ellas repiten el

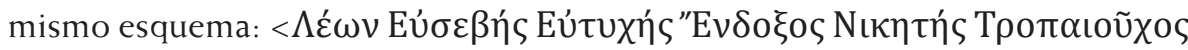

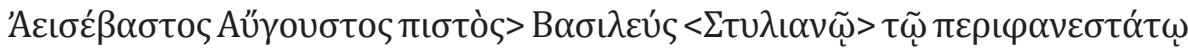

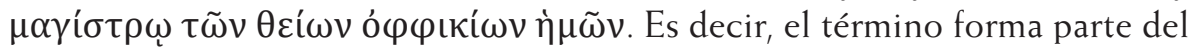

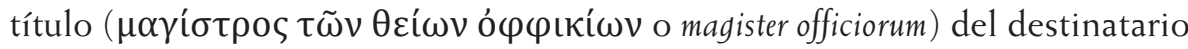
de las Novelas en cuestión (y de la mayor parte de las que forman la Sylloge de las Novelas leoninas), que no es otro que Estiliano Zautzes ( $\Sigma \tau u \lambda \iota \alpha ́$ vos

98 Quedan fuera de nuestra consideración las denominadas Novellae extravagantes, las cuales, en todo caso, tampoco aportan nada significativo al objeto de lo que queremos analizar aquí: vid. al respecto SCHMINCK, "Novellae extravagantes...", cit. 


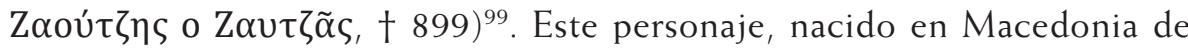
una familia de origen armenio, fue ya un alto funcionario de la corte impe-

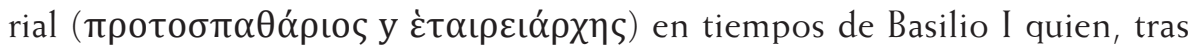
la reconciliación con su hijo León, lo nombró preceptor de este último. A la llegada al trono de León se convirtió en su principal consejero y favorito, sobre todo a partir del matrimonio de León con su hija Zoe Zautzina en 894. Su influencia perduró hasta su muerte en 899 , con juicios variados de los contemporáneos en cuanto a los resultados de su política ${ }^{100}$. León concedió a Estiliano los títulos de $\pi \alpha \tau \rho$ íкıьৎ y $\beta \alpha \sigma \iota \lambda \varepsilon 0 \pi \alpha ́ \tau \omega \rho$, un título este último de compleja etimología y significado dudoso, creado por León específicamente para su favorito y que al parecer no era una mera dignidad o título honorífico, sino un verdadero cargo (officium) ${ }^{101}$, que aparece en el Kletorologion de Filoteo en el primer puesto del ránking de cargos de León ${ }^{102}$, tal vez equivalente a

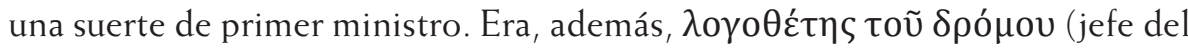
servicio de correos, pero en realidad responsable del servicio diplomático, es decir, una especie de Ministro de Asuntos Exteriores, con la trascendencia que ello tenía en el Imperio bizantino) y también ostentaba, al menos desde 886,

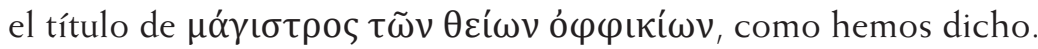

El título resultaba en la época de Léon VI una rareza y un anacronismo. El cargo de magister officiorum ${ }^{103}$ fue introducido por Constantino I (ca. 320) con el fin de servir de cabeza del cuerpo de funcionarios de la administración central del Imperio, y fue ganando progresivamente más competencias y mayor capacidad de influencia: era miembro permanente del consistorium, dirigía los principales

99 Sobre este personaje, vid. Anthony Cutler y AleXAnder KaZHDan, The Oxford Dictionary of Byzantium, cit., vol. III, 2200 (s. v. Zaouzes, Styilianos); además, con más detalle, TouGHER, The Reign of Leo..., cit., pass., esp. 89-109.

100 ANDREAS SCHMINCK, "Frömmigkeit ziere das Werk'. Zur Datierung der 60. Bücher Leons VI", Subseciva Groningana, 3, 1989, 91.

101 Vid. Andreas E. Gkoutzioukostas, "The dignity of basile(i)opator", Fontes Minores 12 2014/2015, 205 ss.; ANDREAS SCHMINCK, "Minima Byzantina", ZSS (R.A.) 132, 2015, 478 ss.

102 Vid. Kletorologion de Filoteo (vid. OiKOnOmides, Les listes...., cit., 100-101).

103 Sobre esta figura, vid. ARTHur EDWARD Romilly BoaK, "The Master of Offices in the Later Roman and Byzantine Empire", Two Studies in Late Roman and Byzantine Administration, New York: MacMillan, Arthur Edward Romilly Boak \& James Eugene Dunlop (eds.), 1924, 1 ss.; , ERNEST STEIN, Histoire du Bas-Empire (trad. fr.), vol. I, Bruges: Desclée de Brouwer, 1959, esp. 119 ss., 177 ss., 240 ss., 283 ss.; vol. II, Bruges: Desclée de Brouwer, 1949, 73, 122 s., 194 ss., 256, 406, 465 ss., 749, 798, 810; MANFRED Clauss, Der Magister Officiorum in der Spätantike, München: Beck, 1980, A. H. M. JONES, The Later Roman Empire, 284-602. A Social, Economic, and Administrative Survey, vols. I-III, Oxford: Basil Blackwell, 1964, 103, 161 , 203, 333 ss., 352, 368 s., 488 ss., 575 ss., 834 s.; Roland DelmaiRe, Les institutions du BasEmpire romain, de Constantin à Justinien I: Les institutions civiles palatines, Paris : Éditions du Cerf/ Éditions du CNRS, 1995, 75 ss.; AlEXANDER KAZHDAN, The Oxford Dictionary of Byzantium, cit., vol. II, 1266-1267 (s. vv. magister officiorum y magistros, con lit.). 
departamentos (scrinia) de la administración imperial (con excepción de los que tenían competencias fiscales), era responsable del servicio de correos y también asumió funciones de responsabilidad de la seguridad del emperador, con autoridad sobre los regimientos de la guardia imperial (scholae palatinae) y los agentes centrales de vigilancia y espionaje (agentes in rebus) ${ }^{104}$, aunque no parece que nunca llegara a ejercer verdaderas funciones militares ${ }^{105}$. Con todo, debido al creciente papel de los agentes y de la guardia imperial, así como por el control que ejercía sobre el cuerpo de los intérpretes (que desempeñaban un papel esencial en las actividades diplomáticas), el magister officiorum acabó por convertirse en la figura central del gobierno imperial, con capacidad de controlar, a través de funcionarios delegados suyos, a las autoridades provinciales en los ámbitos de su competencia. Tenía además amplias funciones de tipo jurídico, con competencias jurisdiccionales en cuanto miembro del sacrum consistorium y asistiendo al quaestor sacri palatii en la elaboración de las constituciones imperiales.

El cargo fue entrando en decadencia a partir del siglo VII, ya que sus amplias funciones se fueron viendo recortadas progresivamente, siendo asumidas por otros tipos de funcionarios especializados ${ }^{106}$. A lo largo de los siglos VIII y IX el cargo acabó convirtiéndose en un mero título honorífico, uno de tantos de los integrantes de la corte imperial.

No parece, por tanto, muy lógico que un personaje de tanto poder como Estiliano Zautzes ostentara un título tan minusvalorado en la jerarquía imperial del siglo IX, y que sea además justamente ese título el que se destaque en la dedicatoria que León hace en sus Novelas destinadas a él. La única explicación plausible se encuentra en el afán emulativo del emperador respecto a la figura de Justiniano. León nombra a Estiliano magister officiorum y le designa así en el encabezamiento de las Novelas como si este fuera un nuevo Triboniano (y así, por tanto, León un nuevo Justiniano) ${ }^{107}$.

104 Sobre estos funcionarios, vid. últimamente ANTONIO FERNÁNDEZ DE BuJÁN, "Contribución al estudio de la vigilancia, seguridad ciudadana y orden interno en el marco de la administración pública romana. Especial referencia a los agentes in rebus", Revista General de Derecho Romano, 25, 2015, 1-20 [online: www.iustel.com].

105 No obstante, también tuvo desde ca. 390 funciones de supervisión de las factorías de armamento y era responsable del abastecimiento y acondicionamiento de las unidades del ejército, con asistencia de oficiales locales, y también tenía jurisdicción sobre los soldados de los limitanei, i. e. unidades militares situadas a lo largo y detrás de las fronteras del Imperio: vid. JONES, The Later Roman Empire..., cit., 575 ss.

106 BuRY, The Imperial Administrative System..., cit., 29.

107 Vid. SCHMINCK, "'Frömmigkeit ziere das Werk'...", cit., 27; TOUGHER, The Reign of Leo...,

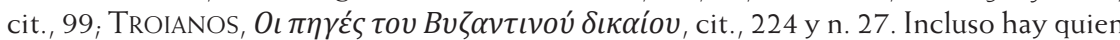
no descarta que las Novelas destinadas a Estiliano Zautzes hubieran sido, en realidad, escritas por este. 
Sea como fuere, lo cierto es que, a los efectos que aquí nos interesan, este es el único uso de la expresión "ó $\varphi \varphi$ íkıov" en las Novelas de Léon, aunque repetido hasta ocho veces a lo largo del texto. No hay más trazas de uso de este vocablo en el resto de la obra ${ }^{108}$, frente a lo que hemos visto en el caso de la Eisagoge (y, por ende, del Prochiron), aun cuando se trata de obras casi coetáneas. Un uso, además, como se ha visto, muy especial y poco significativo desde el punto de vista de la designación del cargo público en esa obra (ya que se trata, en realidad, de un mero formulismo, y además de un arcaísmo que no se corresponde bien ni con la estructura jerárquica del Imperio en ese momento, ni mucho menos con la relevancia política del personaje al que el término se está refiriendo). Este hecho requiere sin duda una explicación.

\section{CONCLUSIONES}

A la vista de lo expuesto, nos encontramos, pues, con seis usos muy variados del término "ó $\varphi \varphi$ íкıо " en la Eisagoge, que responden a la mayoría de los significados del vocablo en el lenguaje del derecho romano clásico y postclásicojustinianeo. Hay dos casos en los que el término significa "cargo" en sentido amplio, es decir, un conjunto de atribuciones y, sobre todo, deberes que incumben a alguien por el hecho de tener que ocuparse de asuntos de otros con una dimensión comunitaria; o sea, el primero de los significados del término en las fuentes romanas que hemos identificado más arriba; en el primero de esos casos (Eis. 16.7), al venir el término "ó $\varphi \varphi$ íkıov" complementado por el

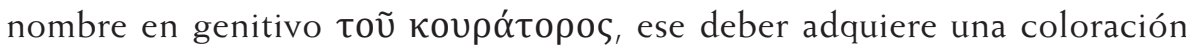
privada que, en sí mismo, no tiene, puesto que depende de factores externos que ese officium se considere publicum o privatum; en el segundo (Eis. 23.17), en cambio, ese carácter neutro del término se observa más claramente, toda vez que en el texto hace alusión tanto a cargos públicos (funcionarios como el

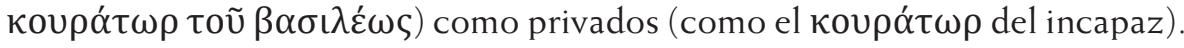
En tres casos encontramos este significado de deber constreñido al ámbito de la función pública, es decir, ó $\varphi \varphi$ íkıv como término que designa al conjunto de competencias o atribuciones de un funcionario público, que es, obviamente, el significado del que hemos partido y que resulta predominante en las fuentes clásicas en tanto que terminus technicus de la lengua jurídica: estos tres casos son Eis. 6.7, 15.6 y 23.18. Por fin, encontramos un solo caso (Eis. 6.6) en que el término es usado en el sentido de "conjunto de funcionarios", es decir, personal subalterno al servicio de una autoridad pública, o sea, la cuarta acepción de la palabra según la enumeración antedicha y que, como ya hemos afirmado,

108 Algo parecido sucede ya en las Novelas de Justiniano, puesto que en ellas, de las diez veces en que aparece el vocablo, cinco corresponden a inscriptiones. 
resulta el uso predominante a primera vista en la legislación postclásica romana ${ }^{109}$. En suma, encontramos, pues, que en esta obra postclásica bizantina predominan los usos de este término más propios de la tradición clásica que de la postclásico-justinianea ${ }_{i}$ hay, en este sentido, una mirada más intensa hacia la tradición jurisprudencial antigua que hacia los desarrollos legislativos más recientes, lo cual, por otra parte, no debería resultar extraño, teniendo en cuenta que la Eisagoge es más bien una obra doctrinal que legislativa propiamente dicha, aunque tuviera en principio la pretensión de constituir un texto jurídicamente vinculante ${ }^{110}$. Es significativo, en todo caso, que todas las apariciones de este término en la obra, salvo uno (Eis. 15.6), responden a la traducción del vocablo "officium" (con diversas variantes) aparecido en textos del Digesto. Y la única aparición que no responde a este esquema, sino que se produce de forma independiente del texto de la fuente clásica, se trata posiblemente de un comentario de un antecessor justinianeo perfectamente familiarizado con el lenguaje de la jurisprudencia clásica. De ahí, por tanto, que la expresión constituya un ejemplo por excelencia de latinismo inserto en el núcleo de las fuentes jurídicas bizantinas del Imperio medio, y que no fue objeto de exbelenización tanto como otros, tal vez porque su uso asentado también en el seno de la Iglesia bizantina ${ }^{111}$ lo hacía un término más asimilado que otros de la tradición jurídica.

Por el contrario, en las Novelas de León VI solo encontramos un uso único y muy particular del término en cuestión, que no responde en absoluto al que observamos en la Eisagoge (y, por ende, en el Prochiron). En este caso, el silencio de la obra resulta muy elocuente. Como hemos visto en el caso de la Eisagoge, prácticamente todos los usos de la expresión obedecen a una traducción directa del término latino "officium" que el reelaborador bizantino ha encontrado en las fuentes justinianeas. Es decir que no hay, al menos por lo que se deduce de estas obras, un uso espontáneo de la palabra por parte de los native speakers grecoparlantes del Imperio Bizantino, ni siquiera entre los conocedores de la lengua jurídica. El latinismo funciona aquí como un mero calco lingüístico de la expresión originaria. El único caso de uso de la palabra que observamos en las Novelas de León va en esta misma dirección: el término forma parte simplemente de la traducción oficial de ese título y esa función procedente del Bajo Imperio romano en el lenguaje funcionarial bizantino. Puesto que en el resto de la obra no hay traducciones de expresiones originarias latinas, como en el

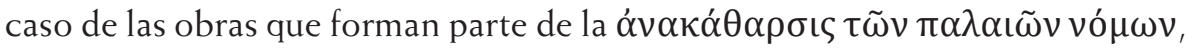
sino que las Novelas de León se presentan como algo original y reformador de

109 Vid. supra en el texto y nota 48.

110 Sobre su verdadero valor legislativo o no, la controversia es también grande: vid. al respecto Signes CODOÑER y ANDRÉS SANTOS, La Introducción al Derecho (Eisagoge)..., cit., 165-182, y, recientemente, VAN BoCHOVE, "Some Byzantine Law Books...", cit.

111 Vid. supra en el texto y nota 51. 
la legislación justinianea, no existe razón para emplear de nuevo este vocablo en el conjunto del texto.

Las Novelas de León acuden, de hecho, a otros términos más próximos a la realidad lingüística de su tiempo para designar el caso del "cargo público" con carácter general. En efecto, una rápida búsqueda por medio del TLG nos permite comprobar que otros términos relacionados lingüísticamente con el contenido de ó $\varphi \varphi$ ́́́кıv aparecen empleados con mayor o menor frecuencia en la obra:

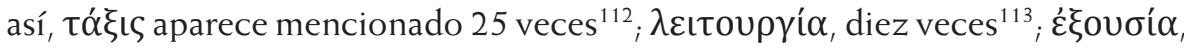

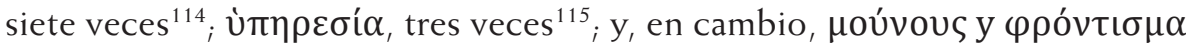

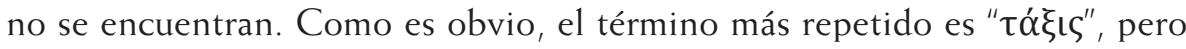
ello no significa necesariamente que sea el preferido en la obra para aludir a los cargos públicos, puesto que, evidentemente, el campo semántico de esta palabra es mucho más amplio que el de las otras $\mathrm{y}$, por tanto, como terminus technicus del lenguaje jurídico-administrativo tiene un menor valor. Asimismo, hay que recordar que el término " $\lambda \varepsilon \iota \tau o u \rho \gamma \alpha^{\prime} \alpha$ " (al igual que el "officium" latino) presenta cada vez con mayor frecuencia un significado estrictamente litúrgico (valga la redundancia), es decir, encuadrado en el marco de la sacralidad, y nada tiene que ver con un sentido jurídico-administrativo ${ }^{116}$.

Se trataría ahora de examinar si estos termini technici encuentran acomodo en nuestras fuentes, y particularmente en este caso en las Novelas de León, puesto que es aquí donde la ausencia de toda referencia a "ó $\varphi \varphi$ íkıov" hace particularmente evidente la necesidad de conjugar otros términos para aludir a los cargos públicos, en el sentido del officium publicum romano. Sería necesario hacer un estudio pormenorizado de todas las apariciones de cada uno de estos términos para poder determinar con exactitud cuál o cuáles de ellos son los preferidos para referirse a estas cuestiones y qué matices los diferencian, también con los usos tradicionales contenidos en las obras de los antecessores

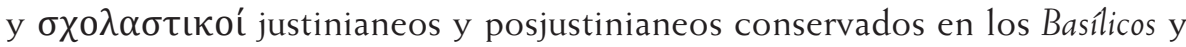
sus escolios. Esta tarea desbordaría con mucho la extensión deseable de este trabajo, por lo que no podemos emprenderla en este momento; pero es claro, en cualquier caso, primero, que la ausencia del término "ó $\varphi \varphi$ íкı plica necesariamente la falta de referencias a cargos o empleados públicos en

112 N. L. proem. $(7,18) ; 1(11,10) ; 3(19,22) ; 7(37,21 / 23) ; 8(39,12 / 41,7 / 15) ; 9(43,12) ; 19$ $(77,3) ; 24(93,15 ; 18 / 95,11) ; 27(107,22) ; 37(149,16) ; 47(185,13 / 18) ; 76(267,19) ; 79$ $(273,2 / 9) ; 86(289,11 / 15 / 291,4) ; 87(291,15) ; 106(347,12)$ (citamos por la edición de Noailles \& Dain, cit., con referencia a página y línea).

113 N.L. $3(21,5 / 15) ; 4(23,4 / 14) ; 12(51,21 / 24) ; 16(63,5) ; 46(183,19) ; 68(247,11) ; 98(323$, 11).

114 N.L. $1(13,24) ; 5(29,3) ; 10(45,19) ; 25(97,14 / 99,13) ; 37(149,14) ; 106(349,13)$.

115 N.L. $29(117,18) ; 68(249,10 / 11) ; 79(273,11)$.

116 Vid., como ejemplo significativo de lo que decimos, el lema 'Liturgy' de The Oxford Dictionary of Byzantium (TAFT, ROBERT F., vol. II, 1240-1241). 
la obra de León VI, y, en segundo lugar, que esas referencias ya parecen completamente exbelenizadas en esta obra, como la comparación con los usos del Prochiron y, sobre todo, la Eisagoge demuestra ${ }^{117}$. Con todo, la determinación de hasta qué grado el lenguaje jurídico bizantino estrictamente griego se ha tecnificado en las Novelas, con el ejemplo de la referencia al "cargo público" en abstracto, debe quedar todavía pendiente de una investigación más profunda.

\section{BIBLIOGRAFÍA}

AHRWEILER, HÉLÈNE. "Recherches sur l'administration de l'empire byzantin aux IX $\mathrm{X}^{\mathrm{e}}$ siècles", Bulletin de Correspondence Hellénique 84, 1960, pp. 1-109 (= Études sur les structures administratives et sociales de Byzance, London 1971, VIII).

ANDRÉS SANTOS, FRANCISCO J. "El gobernador provincial en algunas fuentes jurídicas bizantinas", Hacia un Derecho Administrativo y Fiscal Romano II, Madrid: Dykinson, A. Fernández de Buján (dir.), G. Gerez KraEMER (ed.), 2013, pp. 39-47.

ANDRÉS SANTOS, FRANCISCO J. "'A $\rho \chi 0 v$ en algunas fuentes jurídicas bizantinas", en Ianua Classicorum. Temas y formas del Mundo Clásico, vol. III, Madrid: SEEC, 2015, pp. 119-126.

Andrés SANTOS, FranCiSCO J. "La Eisagoge de Focio, un compendio jurídico bizantino del siglo IX", Revista General de Derecho Romano, 9, 2007 (www.iustel.com).

Ashburner, WAlter. "A Byzantine Treatise on Taxation", Journal of Hellenistic Studies 25, 1925, pp 76-84.

Bartol, FrancisCO. "Leo VI Philosophus adversus Iustinianum?", SDHI, 73, 2007, pp. 445-450.

117 El estudio de los usos de los términos mencionados en estas dos obras arroja los siguientes datos: en la Eisagoge, $\tau \alpha \dot{\xi} \xi ı$ aparece 28 veces (Eis. proem. [2 veces], 3.11, 4 rubr., 7.1/2 [2 veces] $8,9.14,11 \mathrm{rubr} ., 11.1$ [cinco veces] $/ 8$ [dos veces], 12.18, 15.6, 17.1/5/6/8/13/16, $19.6,28.11,33.19$ ), $\dot{\varepsilon} \xi o u \sigma i ́ \alpha, 21$ veces (Eis. proem. [dos veces], 3.11, 4.11, 5.1/7, 6.2/3, 9.8

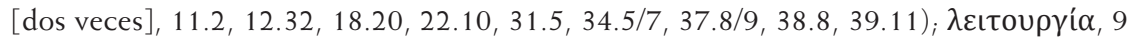

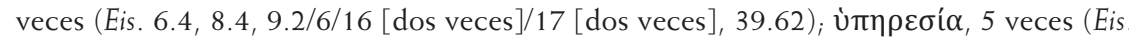

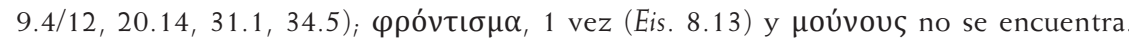

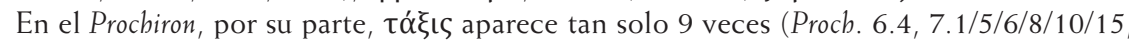

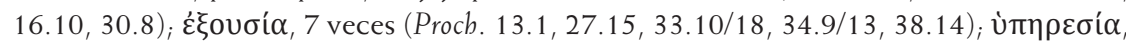
4 veces (Proch. 10.11, 22.1, 33.9 [dos veces]); $\lambda \varepsilon \varepsilon$ troupyía, una sola vez (Proch. 38.63) y $\mu$ oúvous y $\varphi \rho o ́ v \tau ı \sigma \mu \alpha$ no aparecen. Como puede observarse, en estas dos obras, en comparación con las Novelas de León, el término " $\lambda \varepsilon \imath \tau o u \rho \gamma i ́ \alpha$ " tiene una presencia mucho menos significativa, lo que ya de por sí nos da una idea de que en la obra de León VI su sentido ha de ser predominantemente litúrgico-religioso, y no jurídico-administrativo. 
Basilicorum Libri LX. Series A, vols. I-VIII: Textus. Series B, vols. I-IX: Scholia, Groningen et al.: J.B. Wolters, Hermann J. Scheltema, Nicolaas van der Wal, Douwe Holwerda (eds.), 1955-1988.

Boak, Arthur Edward Romilly. "The Master of Offices in the Later Roman and Byzantine Empire", Two Studies in Late Roman and Byzantine Administration, New York: MacMillan, Arthur Edward Romilly Boak \& James Eugene Dunlop (eds.), 1924, pp. 1-160.

Boak, Arthur Edward Romilly, s. v. 'Officium', Pauly \& Wissowa (eds.), Realenzyclopedie der classischen Altertumswissenschaft, XVII-2, Stuttgart: Alfred Fruckenmüller, 1937, pp. 2045-2056.

BREHIER, LOUIS. Las instituciones del Imperio bizantino (trad. esp. J. Almoina), México: Unión Tipográfica Ed. Hispano Americana, 1956.

BurY, JOHN B. The Imperial Administrative System in the Ninth Century, with a Revised Text of the Kletorologion of Pbiloteos, London, 1911; reimpr. New York: Burt Franklin, 1958.

CanCELl, FIlipPO. "Saggio sul concetto di officium in diritto romano", Rivista Italiana perle Scienze Giuridiche 9 (=92), 1957-1958, pp. 351-402.

Cancelli, Filippo, F. Cancelli. "Nota preliminare sull'officium civile", Studi giuridici in memoria di Filippo Vassalli, vol. I, Milano: Unione Tipografico-editrice Torinese, 1960, pp. 229-246.

Cancelli, FilipPO, s. v. 'Ufficio (diritto romano)', Enciclopedia del Diritto, vol. XLV, Milano: Giuffrè, 1992, pp. 599-641.

Cervenca, Giuliano. "Sull'uso del termine 'officium' nella legislazione postclassicogiustinianea", Studi in onore di Giuseppe Grosso, vol. III, Torino: Giappichelli, 1970, pp. 206-243.

Cheynet, JeAn-Claude. Le monde byzantin, II. L'empire byzantine (641-1204), Paris: PUF, 2006.

Clauss, Manfred. Der Magister Officiorum in der Spätantike, München: Beck, 1980.

CREMADES, IGNACIO. El officium en el Derecho privado romano. Notas para su estudio, León: Servicio de Publicaciones de la Universidad, 1988.

DARROUZÈs, JEAN. Recherches sur les ó $\varphi \varphi \iota_{k} \iota \alpha$ de l'Église byzantine, Paris: Institut Français d'Études Byzantines, 1970.

Dell'Oro, Aldo. I libri de officio nella giurisprudenza romana, Milano: Giuffrè, 1960. 
Delmaire, Roland. Les institutions du Bas-Empire romain, de Constantin à Justinien I: Les institutions civiles palatines, Paris : Éditions du Cerf/Éditions du CNRS, 1995.

DÖLGER, FRANZ JOSEPH. Beiträge zur Geschichte des byzantinischen Finanzverwaltung, besonders des 10. und 11. Jabrbunderts, Leipzig-Berlin: Teubner, 1927 (reimpr. Hildesheim: Olms, 1960).

Du CANGE, Sieur (Charles du Fresne). Glossarium ad Scriptores Mediae et Infimae Graecitatis, vol. I, Lugduni: Apud Anissonios, Joan. Posuel \& Cl. Rigaud, 1688.

FERnÁNDEZ de Buján, Antonio. "Contribución al estudio de la vigilancia, seguridad ciudadana y orden interno en el marco de la administración pública romana. Especial referencia a los agentes in rebus", Revista General de Derecho Romano, 25, 2015 , pp. 1-20 [online: www.iustel.com].

FERnÁndeZ de Buján, Antonio. "Derecho Administrativo Romano: instituciones, conceptos, principios y dogmas", Revista General de Derecho Romano 16, 2011 [online: www.iustel.com]

FERnÁndeZ de BujÁN, ANTONIO. "Hacia un tratado de Derecho administrativo y fiscal romano", Hacia un Derecho Administrativo y Fiscal Romano, Madrid: CEU/Dykinson, A. Fernández de Buján (dir.), G. Gerez Kraemer \& B. Malavé Osuna (eds.), 2011, pp. 13-51.

FERnÁNDEZ DE BUJÁN, ANTONIO. "Instituciones, hechos y actividad de orden administrativo en la experiencia jurídica romana', Derecho administrativo bistórico, Santiago de Compostela: Escola Galega de Administración Pública, Antonio Fernández de Buján (dir.), 2005, pp. 119-157.

FERnÁNDEZ De BujÁn, ANTONIO. Derecho público romano. Recepción, Jurisdicción y Arbitraje, Cizur Menor (Navarra): Civitas-Thomson Reuters, 13ª ed., 2010.

FÖGEN, MARIE-THERESE. "Reanimation of Roman Law in the ninth century: remarks on reasons and results", Byzantium in the Ninth Century. Dead or Alive? Papers from the Thirtieth Spring Symposium of Byzantine Studies, Birmingham: Routledge, Leslie Brubaker (ed.), 1996, pp. 11-22.

Frosini, VitTorio, s. v. 'Officio', Novissimo Digesto Italiano, vol. XI, Torino: Unione tipografico-editrice torinese, 1965, pp. 773-777.

Gkoutzioukostas, Andreas E. "The dignity of basile(i)opator", Fontes Minores 12, 2014/2015, pp. 205-233.

Gómez Royo, EnRIQUE. "Introducción al Derecho bizantino", Seminarios Complutenses de Derecho Romano 8, 1996, pp. 139-208. 
GUILLAND, RODOLPHE. Recherches sur les institutions byzantines, vol. I, Berlin/Amsterdam: Akademie Verlag/Hakkert, 1967.

GuILlou, André. La civilisation byzantine, Paris: Arthaud, 1974.

HaLdon, JOHN. "Structures and administration", en, The Oxford Handbook of Byzantine Studies, Oxford: OuP, Elisabeth Jeffreys, John Haldon \& Robin Cormack (eds.), 2008, pp. 539-551.

Heimbach, Karl Wilhelm ERnSt. Basilicorum libri LX, vol. II, Lipsiae: Joh. Ambros. Bartii, 1840 (reimpr. digit. M. A. Fino: http://www.ledonline.it/rivistadirittoromano/).

Heumann, Hermann GotTlieb y SeCKel, Emil. Handlexikon zu den Quellen des römischen Rechts, Graz: Akademischer Druck- und Verlagsanthalt, 10 ed., 1958 (= Jena: Gustav Fischer, $9^{\circ}$ ed., 1907).

Jones, A. H. M. The Later Roman Empire, 284-602. A Social, Economic, and Administrative Survey, vols. I-III, Oxford: Basil Blackwell, 1964.

JONES, A. H. M. The Later Roman Empire, 284-602. A Social, Economic, and Administrative Survey, vols. I-III, Oxford: Basil Blackwell, 1964.

Jus Graecoromanum, vols. I-VIII, Athenai: Georgios Fexis \& filii, Ioannes D. Zepos y Panagiotes I. Zepos (eds.), 1931.

KODER, JOHANNES. Das Eparchenbuch Leons des Weisen. Enführung, Edition, Übersetzung und Indices, Wien: Verlag der Österreichischen Akademie der Wissenschaften, 1991.

KOLIAS, GeORG. Ämter- und Würdenkauf im früb-und mittelbyzantinischen Reich, Athen: Verlag der Byzantinisch-neugriechischen Jahrbüchern, 1939.

LeCrivain, CHARles, s. v. 'Officium/Officiales', Dictionnaires des antiquités grecques et romaines d'après les textes et les monuments, Paris: Hachette, Charles Daremberg \& Edmond Saglio (dirs.), 1904, pp. 155-156.

Lenel, Otto. Palingenesia iuris civilis, vols. I-II, Leipzig: B. Tauchnitz, 1889 (reimpr. Graz: Akademische Druck- und Verlagsanstalt, 1960).

LOKIN, Jan H. A. y VAn Bochove, ThOmas ERnst. "Compilazione - educazione purificazione. Dalla legislazione di Giustiniano ai Basílica cum scholiis", Introduzione al diritto bizantino. Da Giustiniano ai Basilici, Pavia: IUSS Press, Jan H. A. Lokin \& Bernhard H. Stolte (eds.), 2011, pp. 99-146.

Malafosse, Jehan DE, s. v. 'Épanagogè', en Dictionnaire de Droit Canonique, vol. V, Paris: Libraire Letouzey et Ané, Raoul Naz (dir.), 1953, pp. 354-362. 
MatTino, GiUsePpina. Lex et scientia iuris. Aspetti della letteratura giuridica in lingua greca, Napoli: M. D'Auria Editore, 2012.

Moravcsik, Gyula y Jenkins, Romilly J. H. Constantine Porpbyrogenitus: De administrando imperio, vol. I, Greek Text and English Translation, Washington: Dumbarton Oaks Center for Byzantine Studies, 2 ${ }^{a}$ ed., 1967 (reimpr. 2008), vol. II, Commentary, London: University of London Athlone Press, Romilly J. H. Jenkins et al. (eds.), 1962 (reimpr. Washington: Dumbarton Oaks Center for Byzantine Studies, 2012).

Mortreuil, JeAn ANSELME Bernard. Histoire du droit byzantin ou du droit romain dans l'empire d'Orient depuis la mort de Justinien jusqu'à la prise de Constantinople en 1453, vol. II, Paris, 1843-1846 (reimpr. Osnabrück: Otto Zeller, 1966).

Noailles, Pierre y Dain, Alphonse. Les Novelles de Léon Vi le Sage. Texte et traduction, Paris: Les belles Lettres, 1944

OIKONOMIDES, Nicolas. Les listes de préséance byzantines des IX et $X^{e}$ siècles, Paris: CNRS, Paul Lemerle (dir.), 1972.

Patrologia Cursus Completus. Pars Graeca, vol. CVII, Paris: Garnier Fratres, Jacques Paul Migne (ed.), 1857-1866.

Pertusi, Agostino. Constantino Porfirogenito, De thematibus. Introduzione, testo critico, commento Città del Vaticano (Studi e Testi, 160), 1952.

PIEler, Peter E. "Byzantinische Rechtsliteratur", Die bochspracbliche profane Literatur der Byzantiner, vol. 2, München: Beck, Herbert Hunger (ed.), 1978.

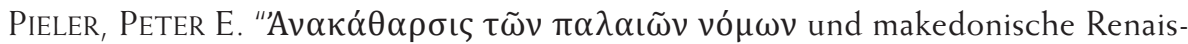
sance", Subseciva Groningana 3, 1989, pp. 61-77.

ReISKE, JOHANN JAKOB. Constantinus Porphyrogenitus: De cereimoniis aulae byzantinae, vols. I-II, Bonn: E. Weber, 1829-1830.

SCHMINCK, ANDREAS. "'Frömmigkeit ziere das Werk'. Zur Datierung der 60. Bücher Leons VI.", Subseciva Groningana, 3, 1989, pp. 79-114.

SCHMINCK, ANDREAS. "Leges ou nomoi? Le choix des princes slaves à l'époque de Pho-

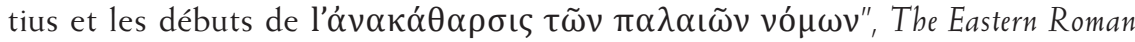
Empire and the Birth of the Idea of State in Europe/L'Empire romain d'Orient et la genèse de l'idée d'État en Europe, London: Esperia, Spyridion Flogaitis \& Antoine Pantélis (eds.), 2005, pp. 309-316.

SCHMINCK, ANDREAS. "Minima Byzantina", ZSS (R.A.) 132, 2015, pp. 469-483.

SCHMINCK, ANDrEAS, "Novellae extravagantes Leons VI.", Subseciva Groningana 4, 1990, 195-209. 
SCHMINCK, ANDREAS. "The beginnings of the 'macedonian' dynasty", Byzantine Macedonia. Identity, Image and History (Papers of the Melbourne Conference, July 1995), Melbourne: Australian Association of Byzantine Studies/Australian Catholic University, John Burke \& Roger Scott (eds.), 2000, pp. 61-68.

SCHMINCK, ANDREAS. Studien zu mittelbyzantinischen Rechtsbüchern, Frankfurt am Main: Löwenklau Gesellschaft e. V., 1986.

Signes Codoñer, JuAn y Andrés SAntos, Francisco J. La Introducción al Derecho (Eisagoge) del patriarca Focio, Madrid: CSIC, Nueva Roma (Biblioteca Graeca et Latina Aevi posteriores, 28), 2007.

Signes Codoñer, Juan. "The Corpus of Leo's Novels: Some Suggestions Concerning Their Date and Promulgation", Subseciva Groningana 8, 2009, pp. 1-33.

Signes Codoñer, JuAn, J. Signes Codoñer. "Las Novelas de León VI el Sabio", Introduzione al diritto bizantino. Da Giustiniano ai Basilici, Pavia: IUSS Press, Jan H. A. Lokin \& Bernhard H. Stolte (eds.), 2011, pp. 267-321.

STEIN, ERNEST. Histoire du Bas-Empire (trad. fr.), vol. I, Bruges: Desclée de Brouwer, 1959.

Stolte, Bernard H. y Meijering (eds.). "The Prooimion of the Eisagoge: Translation and Commentary", Subseciva Groningana 7, 2001, pp. 91-155.

The Oxford Dictionary of Byzantium, vols. I-III, New York et al.: OUP, Alexander Kazhdan (ed.), 1991.

Tougher, Shaun. The Reign of Leo VI (886-912). Politics \& People, Leiden, New York, Köln: Brill, 1997.

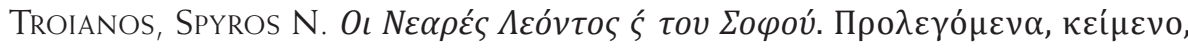

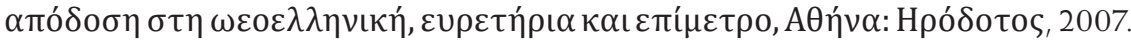

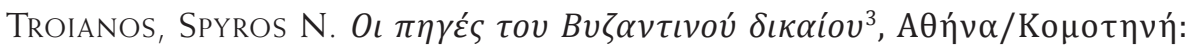
$\sum \alpha \kappa o u \lambda \alpha, 2011^{3}$ (= trad. it. Le fonti del diritto bizantino, Torino: Giappichelli, Pierangelo Buongiorno [ed.], 2015).

Van Bochove, Thomas E. To Date and Not to Date. On the Date and Status of Byzantine Law Books, Groningen: Egbert Forsten, 1996.

VAn Bochove, ThOmas ERnST. "Some Byzantine Law Books. Introducing the Continuous Debate Concerning Their Status and Their Date", Introduzione al diritto bizantino. Da Giustiniano ai Basilici, Pavia: IUSS Press, Jan H. A. Lokin \& Bernhard H. Stolte (eds.), 2011, pp. 239-266.

Van Bochove, Thomas Ernst. "The Basilica between Quellenforschung and Textual Criticism", Textual Transmission in Byzantium: between Textual Criticism and 
Quellenforscbung, Turnhout: Brepols, Juan Signes Codoñer \& Inmaculada Pérez Martín (eds.), 2014, pp. 539-575.

VAN DER WAL, NiCOlAAS y LOKIN. Historiae iuris Graeco-Romani delineatio. Les sources du droit byzantine de 300 à 1453, Groningen: E. Forsten, 1985.

Varela Gil, Carlos. "Los deberes de los administradores públicos en Roma", Revista General de Derecho Romano, 5, 2005 [online: http://www.iustel.com].

Varela Gil, Carlos. El estatuto jurídico del empleado público en Derecho Romano, Madrid: Dykinson, 2007.

VÁRI, RESZÖ. Leonis imperatoris Tactica Const. I-XIV § 38, vols. I-II/1, Budapest: Typis Regiae Universitatis Scientiarum Budapestinensis, 1917-1922.

Verpeaux, Jean. "Hiérarchie et préséances sous les Paléologues", Travaux et Mémoires 1, 1965, pp. $421-437$.

Verpeaux, Jean. Pseudo-Kodinos: Traité des Offices. Introduction, texte et traduction, Paris: Centre Nationale de la Recherche Scientifique, 1966.

Vogt, AlBert. Basil Ier, empereur de Byzance (867-886) et la civilisation byzantine à la fin du IXe siècle, Paris: Picard, 1908.

Vogt, Albert. Constantin VII Porphyrogénète: Le Livre de cérémonies, vols. I-II, Paris: Les belles Lettres, 1935-1940 ( $3^{\mathrm{a}}$ reimpr. 2006).

WeISS, GünTER. Oströmische Beamte im Spiegel der Schriften des Michael Psellos, München: Univ. Inst. für Byzantinistik und Neugriechische Philologie, 1973.

WENGER, LEOPOLD. Die Quellen des römischen Rechts, Wien: Adolf Holzhausens NFG, 1953.

WinkelmanN, FriedHelm. Byzantinische Rang-und Ämterstruktur im 8. und 9. Jabrbundert, Berlin: Akademischer Verlag, 1985.

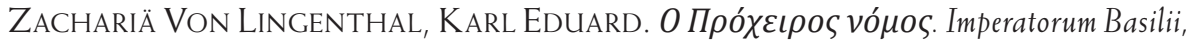
Constantini et Leonis Prochiron, Heidelberg: J. B. Mohr, 1837. 